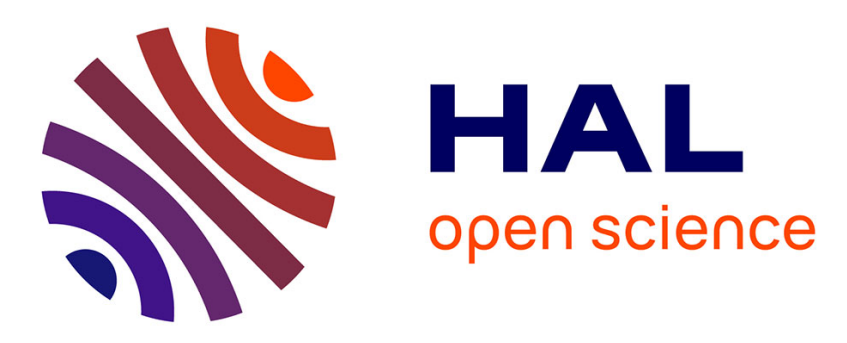

\title{
Modeling adhesive and abrasive wear phenomena in fretting interfaces: A multiphysics approach coupling friction energy, third body and contact oxygenation concepts
}

Pierre Arnaud, Soha Baydoun, Siegfried Fouvry

\section{To cite this version:}

Pierre Arnaud, Soha Baydoun, Siegfried Fouvry. Modeling adhesive and abrasive wear phenomena in fretting interfaces: A multiphysics approach coupling friction energy, third body and contact oxygenation concepts. Tribology International, 2021, 161, pp.107077. 10.1016/j.triboint.2021.107077 . hal-03453434

\author{
HAL Id: hal-03453434 \\ https://hal.science/hal-03453434
}

Submitted on 29 Nov 2021

HAL is a multi-disciplinary open access archive for the deposit and dissemination of scientific research documents, whether they are published or not. The documents may come from teaching and research institutions in France or abroad, or from public or private research centers.
L'archive ouverte pluridisciplinaire HAL, est destinée au dépôt et à la diffusion de documents scientifiques de niveau recherche, publiés ou non, émanant des établissements d'enseignement et de recherche français ou étrangers, des laboratoires publics ou privés. 
Modeling adhesive and abrasive wear phenomena in fretting interfaces: $A$ multiphysics approach coupling friction energy, third body and contact

\title{
oxygenation concepts
}

\author{
Pierre Arnaud $^{\mathrm{a} *}$, Soha Baydoun ${ }^{\mathrm{b} * *}$, Siegfried Fouvry ${ }^{\mathrm{b} * * *}$ \\ ${ }^{a}$ MINES ParisTech, Centre des Matériaux, 63-65 rue Henri-Auguste Desbrueres, F-91003 Évry \\ cedex, France \\ ${ }^{\mathrm{b}}$ Ecole Centrale de Lyon, LTDS Laboratory, 36 av Guy de Collongue, 69130 Ecully, France \\ ${ }^{*}:$ pierre.arnaud@mines-paristech.fr; ${ }^{* *}$ : $\underline{\text { soha.baydoun@ec-lyon.fr }} ;{ }^{* * *}: \underline{\text { siegfried.fouvry@ec- }}$ \\ lyon.fr
}

Abstract: The purpose of this research work is to develop an extended friction-energy Wear approach taking into account the presence of debris layer and adhesive wear by simulating the interfacial dioxygen partial pressure using an Advection-Dispersion-Reaction approach. This multiphysics modeling estimates locally if the fretted interface is running under adhesive or abrasive wear condition. For each situation, a specific energy wear coefficient is considered which finally allows the simulation of the composite adhesive-abrasive (W-shape) fretting scar. A good correlation is observed with former Ti-6Al-4V cylinder-on-flat fretting wear experiments. This model also predicts the transition from pure abrasive to abrasive-adhesive response, $\mathrm{W}$-shape and U-shape fretting scar profiles and for the first time provides reliable estimations of the maximum wear depth extension.

Keywords: Adhesive wear modeling; Fretting Wear; Third body; Friction energy; Contact oxygenation;

Nomenclature

Latin letters

$a$ : debris bed porosity (\%)

$a_{a d}:$ adhesion domain radius $(\mathrm{mm})$

$d_{O}$ : length scale of abrasive wear extension (oxygen distance) $(\mathrm{mm})$

$d_{p}$ : average particle size $(\mu \mathrm{m})$

$a_{w}$ : worn contact radius $(\mathrm{mm})$

$D_{i}$ : dispersion of a gas component " $i$ " $\left(\mathrm{m}^{2} / \mathrm{s}\right)$ 
$D_{\text {mechanical mixing }}$ : mechanical mixing dispersion coefficient $\left(\mathrm{m}^{2} / \mathrm{s}\right)$

$D_{\text {diffusion }, i}$ : molecular diffusion coefficient of a gas component " $i$ " $\left(\mathrm{m}^{2} / \mathrm{s}\right)$

$D_{i, m}$ : effective diffusion coefficient of a gas component " $i$ " in a homogeneous mixture of " $m$ " gases $\left(\mathrm{m}^{2} / \mathrm{s}\right)$

$E d$ : dissipated friction energy (J)

$f$ : sliding frequency $(\mathrm{Hz})$

$F_{n}:$ normal force $(\mathrm{N})$

$F_{n, L}:$ linear normal force $(\mathrm{N} / \mathrm{mm})$

$F_{t}$ : tangential force $(\mathrm{N})$

$F_{t}{ }^{*}$ : tangential force amplitude $(\mathrm{N})$

$F_{n, \max }:$ maximum normal force in the contact $(\mathrm{N})$

$h$ : wear depth $(\mathrm{mm})$

$j$ : iteration of ADR model

$J$ : general flux $\left(\mathrm{kg} / \mathrm{m}^{2} / \mathrm{s}\right)$

$k$ : intrinsic permeability of the debris bed $\left(\mathrm{m}^{2}\right)$

$K$ : incement of Runge-Kutta

$L_{w}$ : lateral width $(\mathrm{mm})$

$n$ : iteration of the numerical wear model

$n_{x}:$ number of the discretized space point

$N$ : cycle number (cy.)

$p:$ contact pressure (MPa)

$P$ : total pressure of the gas mixture $(\mathrm{Pa})$

$P_{i}$ : partial pressure of a gas component " $i$ " $(\mathrm{Pa})$

$\mathrm{R}$ : cylinder radius $(\mathrm{mm})$

$R_{g}$ : gas constant (J/K/mol)

$r_{i}$ : reaction rate coefficient of the gas component " $i$ " $(1 / \mathrm{s})$

$R_{i}$ : decay rate of the gas component " $i$ " by reaction phenomenon $(\mathrm{Pa} / \mathrm{s})$

$S$ : final wear surface $\left(\mathrm{mm}^{2}\right)$

$t$ : time increment (s)

$T$ : temperature (K)

$V$ : wear volume $\left(\mathrm{mm}^{3}\right)$

greek letters

$\alpha$ : energy wear coefficient $\left(\mathrm{mm}^{3} / \mathrm{J}\right)$ 
$\alpha_{L}$ : longitudinal dispersivity (m)

$\beta$ : proportional reaction term $\left(\mathrm{s}^{-1}\right)$

$\beta_{A, n}$ : numerical acceleration jump for wear simulation at iteration " $n$ "

$\gamma$ : power reaction term

$\gamma_{t h}:$ third body conversion factor

$\delta^{*}$ : displacement amplitude $(\mu \mathrm{m})$

$\delta_{g}^{*}$ : sliding amplitude $(\mu \mathrm{m})$

$\varepsilon$ : constant controlling the exponential inflexion

$\varepsilon_{r}$ : convergence parameter

$\Delta_{r} H^{0}:$ standard enthalpy of the reaction $(\mathrm{J} / \mathrm{mol})$

$\Delta_{r} S^{0}:$ standard entropy of the reaction $(\mathrm{J} / \mathrm{k} / \mathrm{mol})$

$\mu$ : nominal coefficient of friction $\left(\mathrm{F}_{\mathrm{t}}{ }^{*} / \mathrm{Fn}\right)$

$\mu_{e}$ : energy friction coefficient

$\mu_{v}$ : gas mixture viscosity $(\mathrm{Kg} / \mathrm{m} . \mathrm{s})$

$\eta$ : tortuosity of the debris bed

$\tau_{\text {max }}:$ maximum cyclic surface shear (MPa)

$v$ : advection velocity of the gas mixture $(\mathrm{m} / \mathrm{s})$

$\varphi(\mathrm{x})$ : local friction energy density $\left(\mathrm{J} / \mathrm{mm}^{2}\right)$

$\varphi^{*}$ : friction power density $\left(\mathrm{W} / \mathrm{mm}^{2}\right)$

$\omega^{*}$ : Archard power density (W/mm²)

\section{1 - Introduction}

Modeling fretting wear in contact assemblies has become a key aspect in many industrial applications. The prediction of the wear volume extension as a function of the contact loadings, materials (i.e. coatings) and even the environmental conditions was extensively investigated during the past decades [1]. First, approaches using Archard law or friction work were developed to describe contact wear through detailed expertise of experimental tests [2]. Hence, the quantitative prediction of fretting wear volume is becoming more and more efficient and reliable. However, in many situations, the prediction of the fretting wear volume is not sufficient to establish the fretting wear endurance of a given assembly. In fact, one of the crucial aspects investigated by the contact-design industries is the prediction of the wear profiles in order to extrapolate the evolution of the maximum wear depth. Knowing the evolution of the latter, it is possible to estimate when the contact assembly is no longer operational or when a surface coating fails [3]. Indeed, the coating endurance is usually related to the loading cycles (i.e. test duration) where the maximum wear depth reaches the substrate interface. The prediction of the wear profile is quite complex. It requires a local description 
of wear and iterative analysis of the wear process. Indeed, the local increment of wear is a function of the local dissipated friction work which itself depends on the contact pressure and wear profile evolutions [4,5,6]. Different numerical approaches have been developed to simulate wear profiles as the semi-analytical approach developed by Nelias and co-authors [7] or the boundary methods developed by Molinari et al. [8]. The most extended approaches are based on finite element approaches whose main advantage is their easy implementation in commercial FEM codes [9].

In the present study, we will consider such numerical strategy combining homemade MathlabPython code with the Abaqus software $[10,11]$. The most recent FEM surface wear strategy consists in computing, for a given worn interface, the friction energy profile dissipated during a fretting cycle and then estimating an increment of wear layer assuming a macroscopic energy wear rate. The increment of wear is transposed to the worn interface using a remeshing procedure and the computation is repeated until the target number of fretting cycles is reached. This approach was recently improved by incorporating a third body layer [12] within the fretted interface. This leads to more realistic wear predictions as the debris layer, by modifying the pressure profile, acts on the local friction energy density and consequently on the wear simulation. First, a static description of the debris layer was considered [13] which was successively improved by considering a dynamic evolution of this layer as a function of the wear extension [14]. Using this approach, good predictions of gross slip cylinder-on-flat fretting wear profiles were achieved only for pure oxidational-abrasive wear processes leading to typical "U-shape" (Fig. 1) fretting-scar morphologies. However, when the loading conditions induce adhesive wear, the wear model was not able to predict the composite "Wshape" structure (Fig. 1).
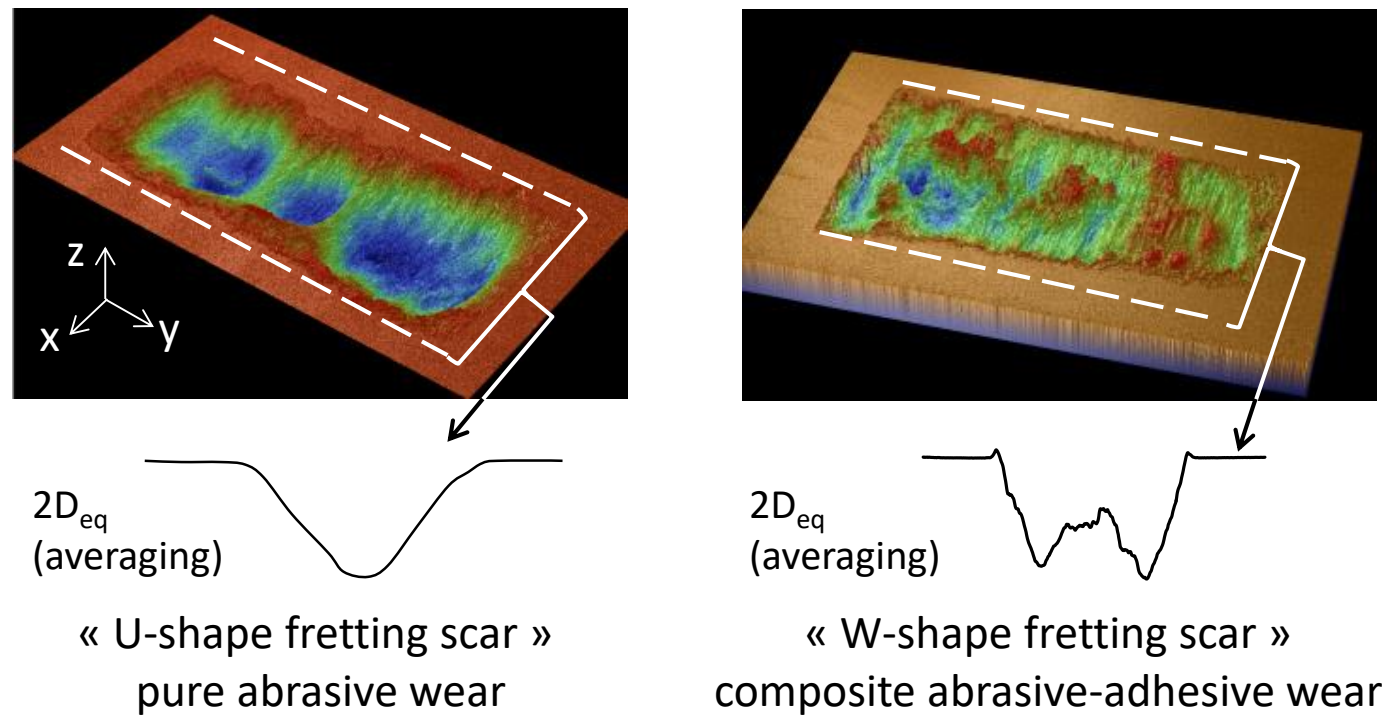

Fig. 1: Illustration of a "U-shape" (pure abrasive wear) and a "W-shape" (composite abrasiveadhesive wear) fretting scar (Ti-6Al-4V cylinder-on-flat contact) [15]. 
The transition from pure abrasive to composite abrasive-adhesive fretting wear processes was recently captured considering the contact oxygenation concept (COC) [15]. This model suggests that the transition from abrasive to adhesive wear occurs when the di-oxygen partial pressure $P_{O_{2}}(x)$ available within the fretted interface at the " $x$ " position becomes lower than a threshold value $P_{O_{2, t h}}$. Indeed, when the concentration of $\mathrm{O}_{2}$ is not sufficient, the oxidation of the fresh metal surface uncovered by the friction is no more effective promoting direct metal-metal interactions and adhesive wear. Therefore, the transition from adhesive to abrasive wear within a fretted interface can be captured by computing the partial pressure profile $P_{O_{2}}(x)$ which is maximum at the contact border (i.e. equivalent to the ambient air) but tends to decrease to a minimum value in the internal part of the contact. This concept was modeled using an Advection-Dispersion-Reaction approach assuming the debris layer as a porous medium crossed by atmospheric gases [16]. An ADR numerical model was developed to simulate the partition between adhesion and abrasion zones in crossed-flat low-alloyed steel contacts. Very nice correlations were achieved through a broad range of fretting loading conditions and contact sizes. The model was also based on a previous experimental investigation [17] suggesting that the threshold $\mathrm{O}_{2}$ partial pressure for steel (i.e. iron) is very low and does not exceed $0.1 \mathrm{~Pa}$, thus $P_{O_{2, t h}}=0.1 \mathrm{~Pa}$.

The purpose of this research work is to develop a combined approach coupling the local surface wear modeling including the presence of a third body layer with the contact oxygenation modeling using an Advection-Dispersion-Reaction approach to explicitly define the partition between adhesive and abrasive wear phenomena in the fretted interface. Then, by considering specific energy wear coefficients for the adhesive and abrasive wear domains, it will be also possible to evaluate how this global approach is able to predict respectively the "U-shape" pure abrasive but also the composite "W-shape" adhesive-abrasive fretting scar morphologies. Besides, by applying this multiphysics approach, the asymptotic decrease of the global wear rate versus the friction power density (i.e. p.v factor) will be formalized confirming former fretting wear experiments.

\section{2-Experimental background}

The given research work intends to simulate the effect of the sliding frequency regarding the fretting wear response of Ti-6AL-4V interface under gross slip condition. To validate this model, a selected number of experimental results compiled in a previous research work [15] was considered. These experiments were performed by keeping constant the cylinder radius $(R=80 \mathrm{~mm})$, the lateral width $\left(L_{w}=8 \mathrm{~mm}\right.$ ), the normal force $F_{n}=8530 \mathrm{~N}$ (i.e. linear normal force: $F_{n, L}=F_{n} / L_{w}=1066 \mathrm{~N} / \mathrm{mm}$ ), the sliding amplitude $\left(\delta_{\mathrm{g}}^{*}= \pm 75 \mu \mathrm{m}\right)$, and the fretting cycles number ( $\mathrm{N}=5000$ cycles) and by varying the sliding frequency from $\mathrm{f}=0.05$ to $10 \mathrm{~Hz}$. Such contact condition leads to a Hertzian contact pressure 
$\mathrm{p}_{\max }=525 \mathrm{MPa}$ and a corresponding Hertzian radius $\mathrm{a}_{\mathrm{H}}=1.29 \mathrm{~mm}$ which will drastically extend with the surface wear. It should be noted that even under the gross slip fretting condition applied here, the fretting sliding amplitude " $\delta_{\mathrm{g}}^{*}$ " is very small compared to the worn contact size " $a_{w}$ " (i.e. $\delta_{\mathrm{g}}^{*} / a_{w} \ll$ $\left.\delta_{\mathrm{g}}^{*} / a_{H}<6 \%\right)$. So, most of the fretted interface is never exposed directly to the ambient air in contrast with the common reciprocating or unidirectional sliding configurations. Fig. 2a illustrates the principle of the test machine used to achieve such experimental data. By recording the evolution of the tangential force $F_{t}$ versus the displacement $(\delta)$ (Fig. $\left.2 b\right)$, the $\left(F_{t}-\delta\right)$ fretting loops can be plotted. This allows the determination of the tangential force $\left(\mathrm{F}_{\mathrm{t}}{ }^{*}\right)$ and the displacement amplitudes $\left(\delta^{*}\right)$. In addition, the sliding amplitude $\left(\delta_{\mathrm{g}}^{*}\right)$, which is measured when the tangential force is zero (i.e. $\delta_{\mathrm{g}}^{*}=\delta$ $\left(F_{t}=0\right)$ ), as well as the dissipated friction energy (Ed) can be both extracted from the fretting loop analysis. In the present investigation, the displacement amplitude was continuously adjusted to keep constant $\delta_{\mathrm{g}}^{*}= \pm 75 \mu \mathrm{m}$. Note that the chosen sliding amplitude is rather large for fretting sliding conditions and systematically induces gross slip sliding conditions as depicted by the quadratic $\left(\mathrm{F}_{\mathrm{t}}-\delta\right)$ fretting loops plotted in Fig. 2 (b). Hence, the W-shape fretting scars which are investigated are not induced by a hypothetical partial slip condition but are well generated by a gross slip condition. The analysis of the fretting loop allows the determination of the so-called energy friction coefficient which better illustrates the fretting wear damage than the conventional $\mu=F_{t} * / F_{n}$ friction ratio:

$\mu_{e}=\frac{E d}{4 \times F_{n} \times \delta_{g}^{*}}$

For the studied Ti-6Al-4V interface, a quasi-constant friction coefficient value is observed whatever the sliding frequency such that $\mu_{e} \approx 0.6$.

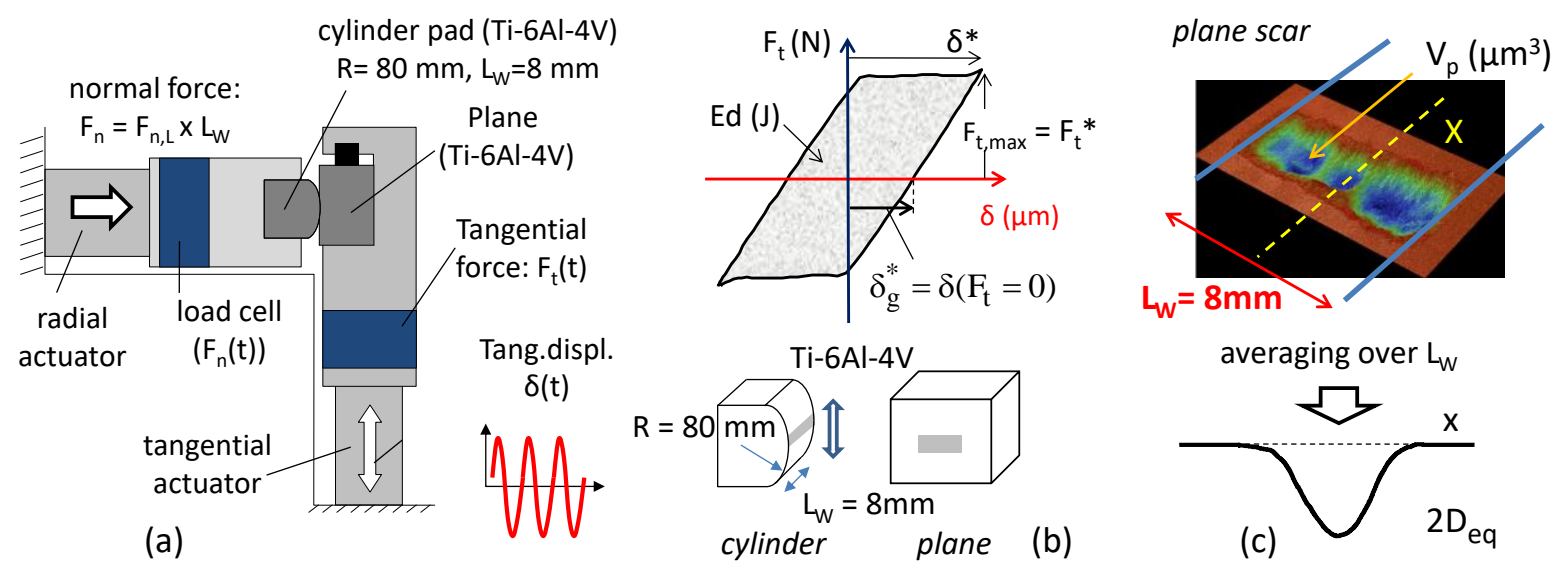

Fig. 2: (a) Illustration of the test experimental setup used to quantify the Ti-6Al-4V cylinder-on-flat fretting wear response [15]; (b) analysis of the fretting cycle and illustration of the geometry of the cylinder and plane test specimens; (c) $3 D$ analysis and extraction of a representative $2 D_{\text {eq }}$ wear profile (illustration for a plane fretting scar). 
At the end of the test, each specimen was cleaned in ultrasonic ethanol bath, then 3D surface profiles of the fretting scars were performed (Fig. 2c). The 3D surface profile allows the determination of the plane and the cylinder wear volumes (i.e. net missing volumes) but also the fretting scar morphology using an averaging procedure along the lateral $L_{w}$ width direction from which equivalent $2 D_{\text {eq }}$ profiles could be extracted. The given investigation will consist in comparing these experimental $2 D_{\text {eq }}$ profiles with the corresponding $2 \mathrm{D}$ simulated profiles. Besides, these $2 D_{\text {eq }}$ profiles allow distinguishing between pure abrasive "U-shape" fretting scars and composite abrasiveadhesive "W-shape" fretting wear processes. Finally, the friction energy wear coefficient $\alpha\left(\mathrm{mm}^{3} / \mathrm{J}\right)$ is extracted by extrapolating a linear relationship between the wear volume and the accumulated friction work dissipated in the interface:

$V=\alpha \times \Sigma E d$

Where $V\left(\mathrm{~mm}^{3}\right)$ is the total wear volume of the interface (i.e. the total net missing volume of the plane and the cylinder) and $\Sigma E d(J)$ is the accumulated friction energy inputted in the interface during the fretting test. Note that the experimental results extracted from [15] which are presently simulated were not duplicated. As matter of fact, many research works $[10,15,16,18]$ confirm the high reproducibility of fretting wear test. This high reproducibility may be explained by the fact that compared to common reciprocating and pin on dick tests, the material volume stressed by the fretting sliding is comparatively very small which reduces in consequence the scattering induced by the material inhomogeneity. As illustrated in Fig. 3 [15], it was shown that low sliding frequencies ( $\mathrm{f}<$ $0.5 \mathrm{~Hz}$ ) promote pure abrasive wear phenomena inducing "U-shape" fretting scar morphologies and relatively high energy wear rates. Alternatively, high frequencies $(f>2 \mathrm{~Hz})$ induce composite abrasiveadhesive wear leading to "W-shape" fretting scar morphologies with direct metal interactions in the inner part of the contact. This transition toward adhesive wear phenomenon also corresponds to a significant decrease of the energy wear coefficient. 


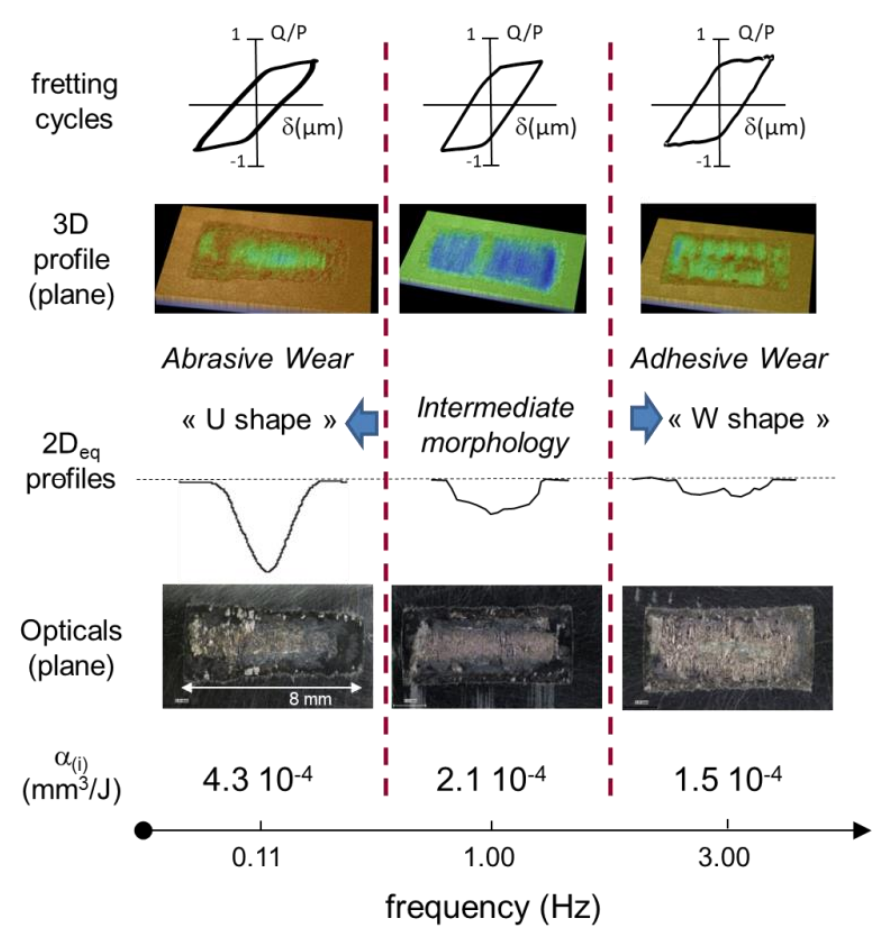

Fig. 3: Evolution of the fretting scar morphology and the wear rate of Ti-6Al-4V interface versus the sliding frequency $\left(R=80 \mathrm{~mm}, F_{n, L}=1066 \mathrm{~N} / \mathrm{mm}, \delta_{g}^{*}= \pm 75 \mu \mathrm{m}, \mathrm{N}=5000\right.$ cycles) (after [15]).

This typical behavior was formalized by comparing the evolution of the friction energy wear rate as a function of the mean friction power density $\left(\varphi^{*}: \mathrm{W} / \mathrm{mm}^{2}\right)$ dissipated in the interface which can be approximated by [15]:

$\varphi^{*}=\frac{E d}{S} \times f=\frac{\Sigma E d}{S \times N} \times f$

Where $S$ is the final contact area measured on the fretting scar after opening the contact.

Experimental investigations underline an initial metal transfer from the plane to the cylinder specimen inducing different fretting wear rates for the plane and the cylinder (Fig. 4) although similar materials are contacted [15]. Asymptotic decrease of the energy wear coefficients could be observed which can be approximated using an exponential function:

$\alpha\left(\varphi^{*}\right)=\frac{\alpha_{a b}-\alpha_{a d}}{\exp \left(\varepsilon \times \varphi^{*}\right)}+\alpha_{a d}$

where $\varepsilon$ is a constant controlling the sigmoid inflexion which is presently fixed at $\varepsilon=11 \mathrm{~J} / \mathrm{mm}^{3}, \alpha_{a b}$ is the wear rate related to a pure abrasive wear process (i.e. when the friction power density tends to zero), $\alpha_{a d}$ is the wear rate related to a pure adhesive wear process suspected when the friction power density tends to infinity. This exponential approximation depicts well the wear rate evolution of the flat counterpart but displays a lager scattering when capturing the cylinder wear response. 
However, it can be physically admitted that similar formulation should be considered for the two counterfaces. Moreover, applying the same formulation is consistent with the global wear modelling of the interface. Besides, considering the same $\varepsilon$ parameter permits the unicity of the evolution of $\alpha\left(\varphi^{*}\right)$. This formulation allows a finite value when $\varphi^{*}$ is zero and an asymptotic $\alpha_{a d}$ value when $\varphi^{*}$ tends to infinity. Note that the large dispersion observed for the cylinder interface may be attributed to the transfer phenomenon which cannot be directly integrated in the actual exponential approximation. To conclude, despite some limitations, the simple exponential approach (eq. 4) appears a convenient approximation of the energy wear evolution as a function of the applied friction power density condition. The transition from pure abrasive U-shape to $\mathrm{W}$-shape composite abrasive-adhesive wear response is observed for a threshold friction power density $\varphi_{t h}{ }^{*}=0.1$ $\mathrm{W} / \mathrm{mm}^{2}$ [15]. From these experimental data the following experimental energy wear coefficient can be identified for the cylinder: $\alpha_{c, a b}=4.110^{-4} \mathrm{~mm}^{3} / \mathrm{J}, \alpha_{c, a d}=0.510^{-5} \mathrm{~mm}^{3} / \mathrm{J}$ and for the plane: $\alpha_{p, a b}=5.110^{-4} \mathrm{~mm}^{3} / \mathrm{J}, \alpha_{p, a d}=1.110^{-4} \mathrm{~mm}^{3} / \mathrm{J}$ respectively (Table 1 ).

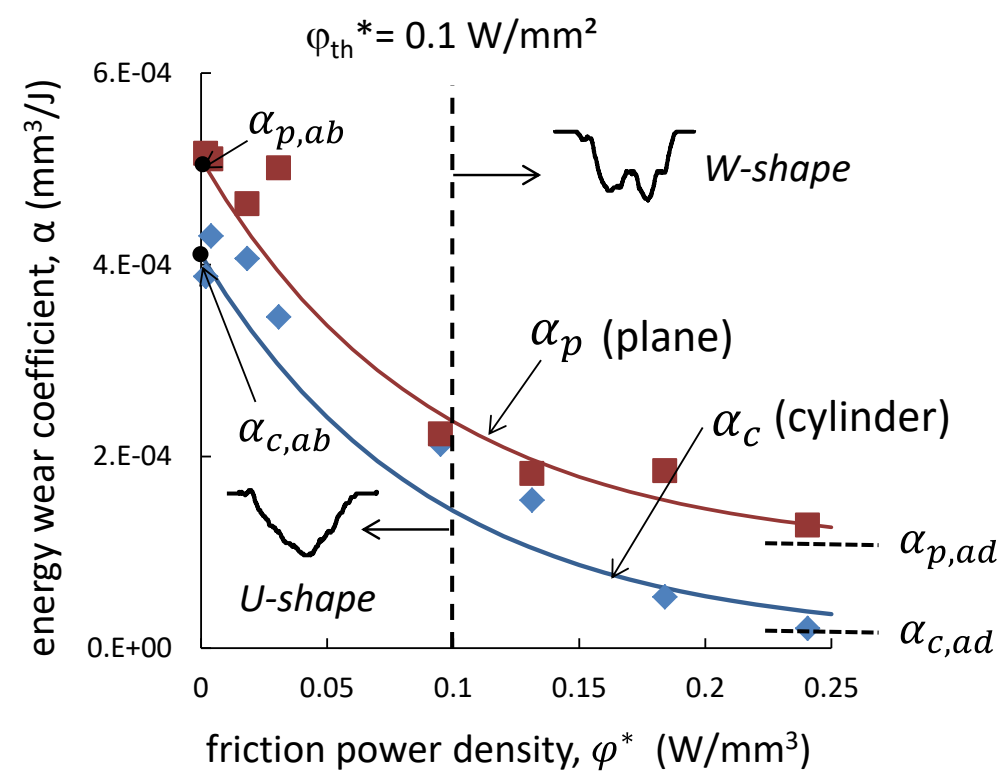

Fig. 4: Evolution of the friction energy wear coefficient of the plane and the cylinder specimens as a function of the friction power density by varying the sliding frequency (experiments: $\diamond$ cylinder, plane; __approximation (Eq. 4, Table 1) (Ti-6AL-4V cylinder-on-flat interface, $R=80 \mathrm{~mm}, F_{n, L}=1066$ $\mathrm{N} / \mathrm{mm}, \delta_{g}^{*}= \pm 75 \mu \mathrm{m}, \mathrm{N}=5000$ cycles, $f$ varying from 0.1 to $10 \mathrm{~Hz}$ [15]). 
Table 1: Compilation of the variables related to the exponential formulation (Eq. 4) to fit the evolution of the energy wear coefficients as a function of the sliding frequency for the experiments (Fig. 4) and the WTO prediction (Fig. 14) (Ti-6AL-4V cylinder-on-flat interface, $R=80 \mathrm{~mm}, F_{n, L}=1066 \mathrm{~N} / \mathrm{mm}, \delta_{g}^{*}=$ $\pm 75 \mu \mathrm{m}, \mathrm{N}=5000$ cycles, $f$ varying from 0.1 to $10 \mathrm{~Hz}$ ).

\begin{tabular}{|c|l|l|l|l|}
\hline experiments (Fig. 4) & cylinder & $\alpha_{c, a b}=4.110^{-4} \mathrm{~mm}^{3} / \mathrm{J}$ & $\alpha_{c, a d}=1.010^{-5} \mathrm{~mm}^{3} / \mathrm{J}$ & $\varepsilon=11 \mathrm{~mm}^{2} / \mathrm{W}$ \\
\hline experiments (Fig. 4) & plane & $\alpha_{p, a b}=5.110^{-4} \mathrm{~mm}^{3} / \mathrm{J}$ & $\alpha_{p, a d}=1.010^{-4} \mathrm{~mm}^{3} / \mathrm{J}$ & $\varepsilon=11 \mathrm{~mm}^{2} / \mathrm{W}$ \\
\hline WTO (Fig. 14) & cylinder & $\alpha_{c, a b}=4.110^{-4} \mathrm{~mm}^{3} / \mathrm{J}$ & $\alpha_{c, a d}=0.910^{-4} \mathrm{~mm}^{3} / J$ & $\varepsilon=22 \mathrm{~mm}^{2} / \mathrm{W}$ \\
\hline WTO (Fig. 14) & plane & $\alpha_{p, a b}=5.110^{-4} \mathrm{~mm}^{3} / \mathrm{J}$ & $\alpha_{p, a d}=1.410^{-4} \mathrm{~mm}^{3} / \mathrm{J}$ & $\varepsilon=22 \mathrm{~mm}^{2} / \mathrm{W}$ \\
\hline
\end{tabular}

\section{3 - Multiphysics modeling}

The former analysis [15] provides a convenient parametric formulation to compare fretting scar and fretting wear rate fluctuations. However, it is factual and semi-empirical. The main objective of this work is to propose a physical justification and a quantitative prediction of such complex adhesiveabrasive fretting wear processes. A multiphysics modeling strategy is introduced here combining the local surface wear simulation using the friction power density concept with the "contact oxygenation" simulation (i.e. local partial pressure of the di-oxygen molecules) in order to monitor the local transition from abrasive to adhesive wear processes. The following section briefly details the principles of these two approaches before deepening the coupling strategy of this multiphysics modelling.

\section{1 - Modeling the surface wear}

Modeling the fretting wear profiles was extensively investigated during the past decades $[7,9,10,11$, $18,19]$. The given $2 \mathrm{D}$ surface wear modeling is directly derived from a previous development fully detailed in [14] (Fig. 5). The surface wear modeling consists in transposing the global wear volume approach at a local point of view where the wear depth at a given $x$ position is assumed proportional to the related accumulated friction energy density $\Sigma \varphi(x)$ through the corresponding energy wear coefficient.

$h(x)=\alpha \times \Sigma \varphi(\mathrm{x})$ 

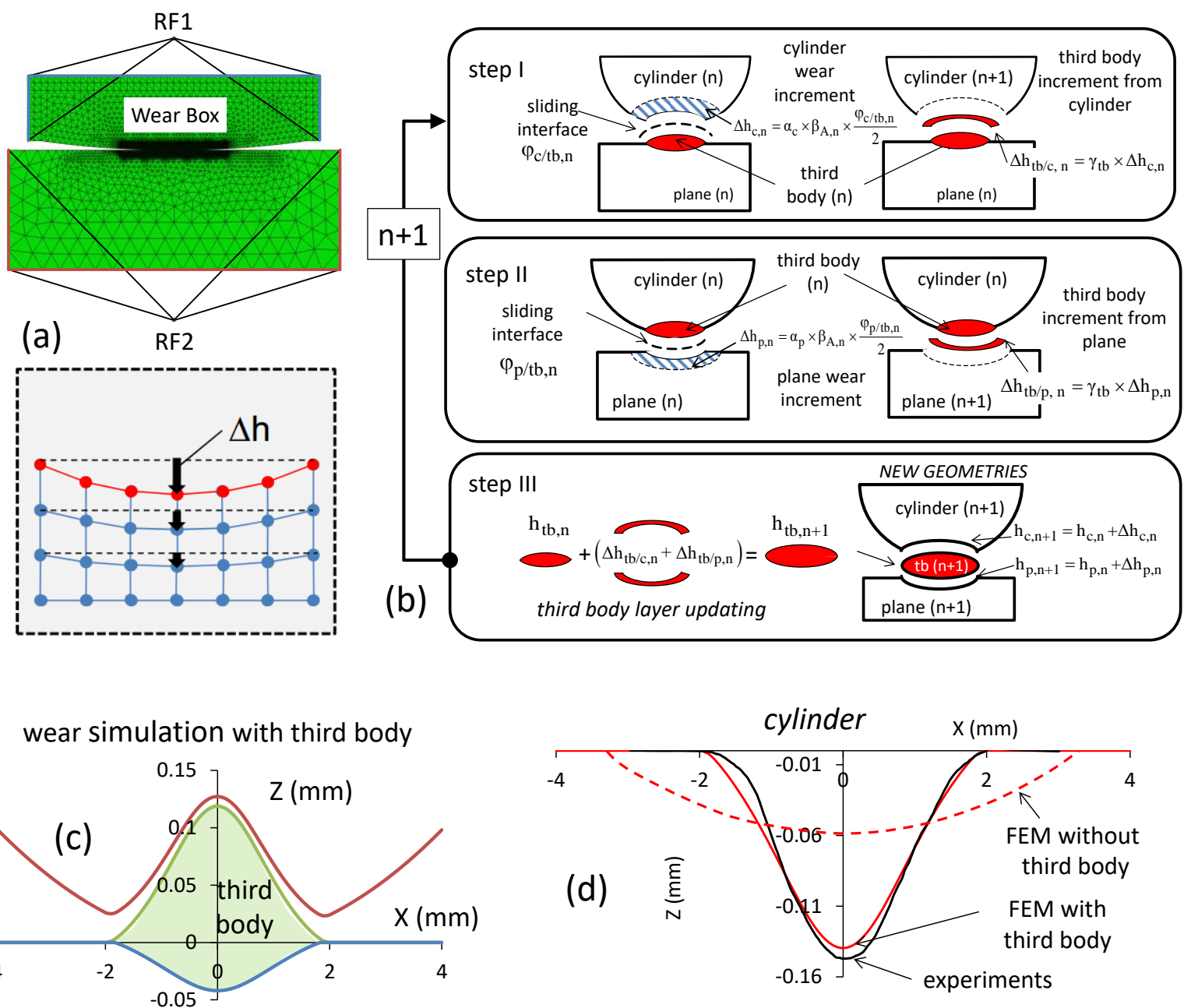

Fig. 5: Illustration of the surface wear modeling: (a) Cylinder-on-flat FEM interface and node translation procedure to update the worn profile after the $n^{\text {th }}$ iteration [14]; (b) description of the three-step procedure to update the plane and the cylinder surfaces in addition to the third body layer; (c) illustration of a simulated U-shape fretting scar taking into account the presence of the third body layer; (d) comparison between experiments (dry Ti-6Al-4V interface) and simulations with and without simulating the third body layer (Third body simulation is required to achieve a reliable prediction).

Transposed to the studied cylinder-on-flat interface, the numerical procedure consists in computing, after a $\beta_{A, n}$ numerical fretting cycle, the increment of wear generated on the plane and the cylinder surfaces at the iteration $n$, respectively:

$\Delta h_{p, n}(x)=\alpha_{p} \times \beta_{A, n} \times \frac{\varphi_{p / c, n}(\mathrm{x})}{2}$

and

$\Delta h_{c, n}(x)=\alpha_{c} \times \beta_{A, n} \times \frac{\varphi_{c / p, n}(\mathrm{x})}{2}$ 
Where $\varphi_{p / c, n}(x) / 2$ is the friction energy density reported on the plane counterpart due to the friction between the plane and the cylinder and $\varphi_{c / p, n}(x) / 2$ is the friction energy density reported on the cylinder due to the friction between the cylinder and the plane. The factor $1 / 2$ is related to the fact that $50 \%$ of the total friction energy $(\varphi(x))$ is assumed to be dissipated in each counterface.

Plane and cylinder friction energy density distributions (i.e. $\varphi_{p / c, n}(x)$ and $\varphi_{c / p, n}(x)$ ) along the $\mathrm{x}$ physical position are slightly different due the relative sliding between each counterface (i.e. plane is assumed fixed and the cylinder moving). Obviously the integration of these two density profiles over the whole fretted interface leads to the same global friction energy (i.e. Ed).

These computations are long and fastidious, therefore to avoid the simulation of each experimental fretting cycle, an acceleration $\beta_{A, n}$ factor is considered. This acceleration factor expresses the number of real (experimental) fretting cycles approximated by each numerical fretting cycle.

In other words, the $\beta_{A, n}$ variable corresponds to the number of experimental fretting cycles imposed on the contact for each simulated numerical cycle. The $\beta_{A, n}$ variable must be chosen large enough to allow fast simulation but small enough to avoid numerical distortions. The acceleration factor can be constant or adjusted as a function of the surface wear extension [11]. In the present investigation $\beta_{A, n}$ was adjusted in order to generate a maximum $3 \mu \mathrm{m}$ wear depth increment after each numerical simulation. The contact geometry at the $N$ numerical cycles is then updated by subtracting the computed increments of the worn thickness from the $n-1^{\text {th }}$ surface profiles, so that a bilateral surface wear simulation could be achieved:

$h_{p, n}(x)=h_{p, n-1}(x)-\Delta h_{p, n}(x)$

$h_{c, n}(x)=h_{c, n-1}(x)-\Delta h_{c, n}(x)$

Both the plane and the cylinder FEM geometries are then updated by applying a remeshing procedure. The final wear profiles are obtained when the number of simulated fretting cycles corresponds to the target (i.e. experimental) fretting cycles' number $(N)$ so that:

$N=\sum_{n=1}^{N_{\text {num }}} \beta_{A, n}$

This approach provides rather good surface wear simulations when the fretting contact is not influenced by the presence of a debris layer as observed in lubrication (like water). However, in dry contact when debris particles display high cohesive properties as in Ti-6Al-4V interface, a thick third body layer is formed modifying, in consequence, the contact pressure and accordingly the wear profile evolution. Although performed under pure abrasive wear conditions, the fretting wear analysis of a dry Ti-6Al-4V interface confirmed the necessity to consider the presence of the third body layer to predict the wear profile. Many researches intend to consider the presence of a debris layer in fretting wear simulation. However, these numerical developments usually consider a static description of the third body. More recently, Arnaud et al. [14] proposed a dynamical description 
where the third body layer is simulated as an additional FEM part entrapped between the plane and the cylinder counterparts. An originality of this approach lies in the fact that this third body layer extends laterally and in thickness as a function of the surface wear extension. Hence, after the $n^{\text {th }}$ numerical fretting cycle, a $\gamma_{t b, n}(x)$ proportion of the worn thickness increment is transposed to the third body layer. On the other hand, the $h_{t b, n}(x)$ thickness of the debris layer at the $x$ position and at the $n^{\text {th }}$ computation iteration evolves such that:

$h_{t b, n}(x)=h_{t b, n-1}(x)+\gamma_{t b, n}(x) \times\left(\Delta h_{p, n}+\Delta h_{c, n}\right)$

Note that the complement of the third body transfer, (i.e. 1- $\left.\gamma_{t b, n}(x)\right)$ corresponds to the proportion of the worn debris eliminated from the interface. Regarding surface wear simulations, similar formulations are considered except in equation (6) where the presence of the third body must be considered so that $\varphi_{p / c, n}(x)$ must be replaced by $\varphi_{p / t b, n}(x)$ and $\varphi_{c / p, n}(x)$ must be replaced by $\varphi_{c / t b, n}$. Here, $\varphi_{p / t b, n}$ is the friction energy density reported on the plane specimen due to the friction between the plane and the third body layer (bottom part) and $\varphi_{c / t b, n}$ is the friction energy density reported on the cylinder counterpart due to the friction between the cylinder and the third body (top part). The third body conversion factor " $\gamma_{t b, n}(x)$ " can be approximated using an elliptic function of the radial distance (i.e. $x$ abscissa) leading to a maximum value at the center of the contact.

This is consistent with the fact that the worn debris generated at the center of the contact displays a higher probability to remain in the third body than the ones formed on the lateral sides where they are more easily ejected. Moreover, the third body concept $[20,21]$ suggests that the third body thickness remains constant when a steady state regime is reached (i.e. the debris ejection flow equals the debris formation flow). This implies an asymptotic decrease of the $\gamma_{t b, n}$ factor from a maximum value around 1 at the beginning of the test (i.e. full debris entrapping condition) until a minimum value around zero when the steady state third-body thickness is established. This aspect was fully discussed in [14] by using a simple power law function to express the surface and the time evolution of $\gamma_{t b, n}(x)$. Using this approach, it was possible to predict well the "U-shape" experimental wear profiles induced by pure abrasive wear conditions. In the given analysis the fretting cycles, the normal force, the sliding amplitude and the contact size were kept constant while varying the sliding frequency. Therefore, as a first approximation, the third body conversion factor was kept constant and calibrated from the pure abrasive surface wear response observed at $f=1 \mathrm{~Hz}$ so that:

$\gamma_{t b, n}(x)=\gamma_{t b}=0.85$

This mechanical model was only validated when a single abrasive wear process is operating within the interface inducing "U-shape" fretting scars. Our objective now is to simulate more complex 
abrasive-adhesive W-shape scar morphologies. To achieve this aspect, a varying distribution of the energy wear coefficient must be implemented in the interface which itself must be monitored as a function of the activation of adhesive or abrasive wear processes. This implies updating this "mechanical" friction energy wear approach with a physicochemical modeling of the tribo-oxidation activation within the interface which in fact consists in simulating the contact oxygenation of the fretted interface.

\section{2 - Modeling the Contact Oxygenation}

\subsection{1 - Constitutive equation}

Composite adhesive-abrasive fretting scar morphologies were observed since the beginning of fretting wear investigation. A paradox of such experimental results was that although most of the interface is never exposed to the ambient air (i.e. the gross slip fretting sliding amplitudes are usually less than $1 / 10$ or $1 / 100$ of the contact size), oxidation wear processes could be observed in a significant part and even over the whole fretted interface depending on the sliding conditions.

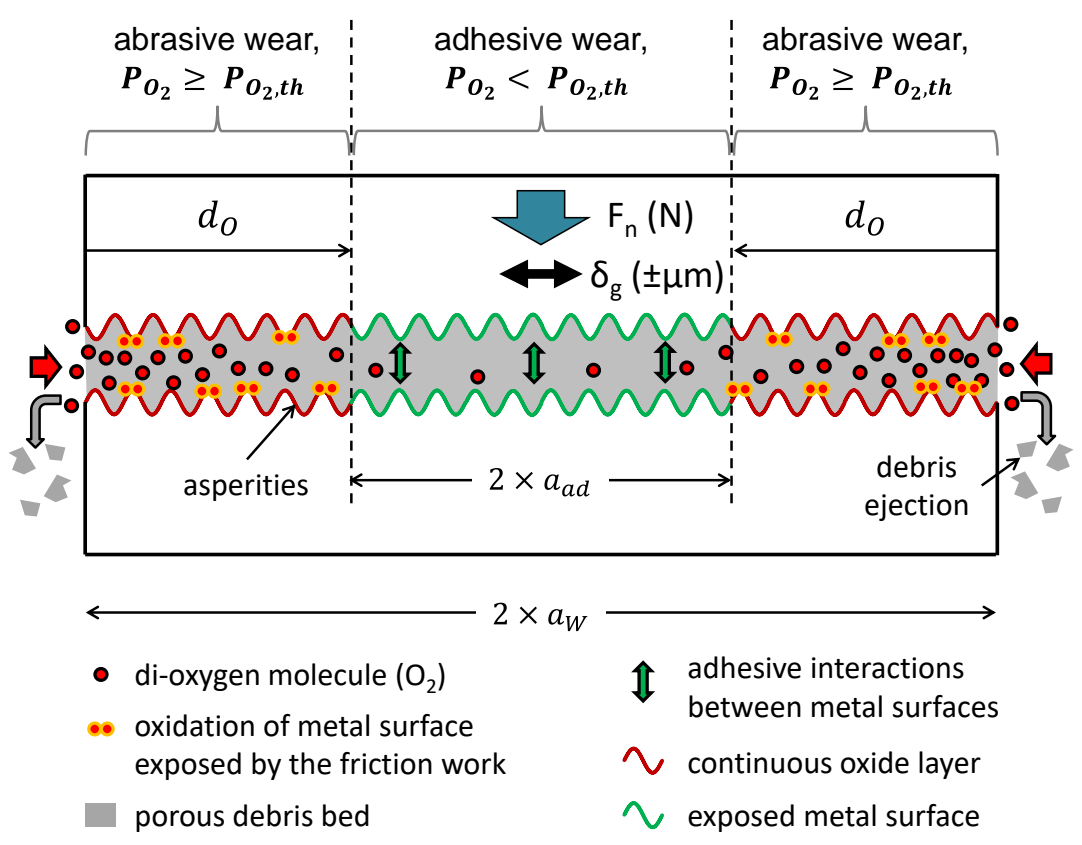

Fig. 6: Illustration of the air distilling process within a fretting interface such that the variable $d_{O}$ expresses the extension of the abrasive wear domain toward the inner part of the contact (After [16, 22]).

Mary et al. [22] examined the effect of the contact pressure on Ti-6Al-4V proposing that this partition between the inner adhesive and the abrasive wear phenomena on the lateral sides could be related to an "air distilling process" as illustrated in Fig. 6 . The idea is that the ambient air diffuses through the porous debris layer and/or the surface roughness interstices from the contact borders toward the internal part of the contact. However, part of the diffusing di-oxygen molecules react with the fresh metal surface uncovered by friction to create the surface oxide layer. Hence, the interfacial di- 
oxygen partial pressure $\left(P_{O_{2}}\right)$ decreases continuously as we move away from the contact borders. Below a threshold value $\left(P_{O_{2, t h}}\right)$, the surface oxidation is no more possible and adhesive wear and metal transfer processes are activated. The authors also suggest that by reducing the presence of $\mathrm{O}_{2}$ molecules, this air distilling process promotes an increase of the $\mathrm{N}_{2}$ partial pressure which in turn triggers a nitriding phenomenon in the internal part of the interface. This air distilling process was observed in steel as well as titanium fretting interfaces. Warmouth et al. [23] considered an equivalent approach referred to as "contact air exclusion" process which confirmed this tendency and proposed that this phenomenon could explain the decrease of the wear rate with the contact size. The larger is the contact size, the larger is the inner adhesive wear and the lower is the global wear rate since abrasive wear rate is usually higher than the adhesive one. Both "air distilling" and "air exclusion" approaches were finally conceptualized through the so-called Contact Oxygenation Concept (COC) developed in [15] consisting in formalizing the transition from abrasive to adhesive wear by comparing the profile of the interfacial di-oxygen partial pressure $P_{O_{2}}(x)$ versus a threshold value:

If $P_{O_{2}}(x) \geq P_{O_{2}, t h}(x)=>$ Abrasive wear

If $P_{O_{2}}(x)<P_{O_{2}, t h}(x)=>$ Adhesive wear

The extension of the lateral abrasive wear domain was quantified experimentally by measuring, through optical or EDX observations, the lateral width $d_{O}$ where black oxide debris could be observed [24] (Fig. 7). The inner adhesive domain was in turn characterized by bright surface metal aspect and low EDX oxygen concentrations. Hence, we can quantify the extension of the abrasive wear domain from the contact border such that:

$d_{O}=x$ when $P_{O_{2}}(x)=P_{O_{2}, t h}$

(i.e. the boundary between the inner adhesive and the external abrasive wear domain). Thanks to this " $d_{O}$ " parameter, it is possible to rationalize the Contact Oxygenation condition of the studied fretting interface. 


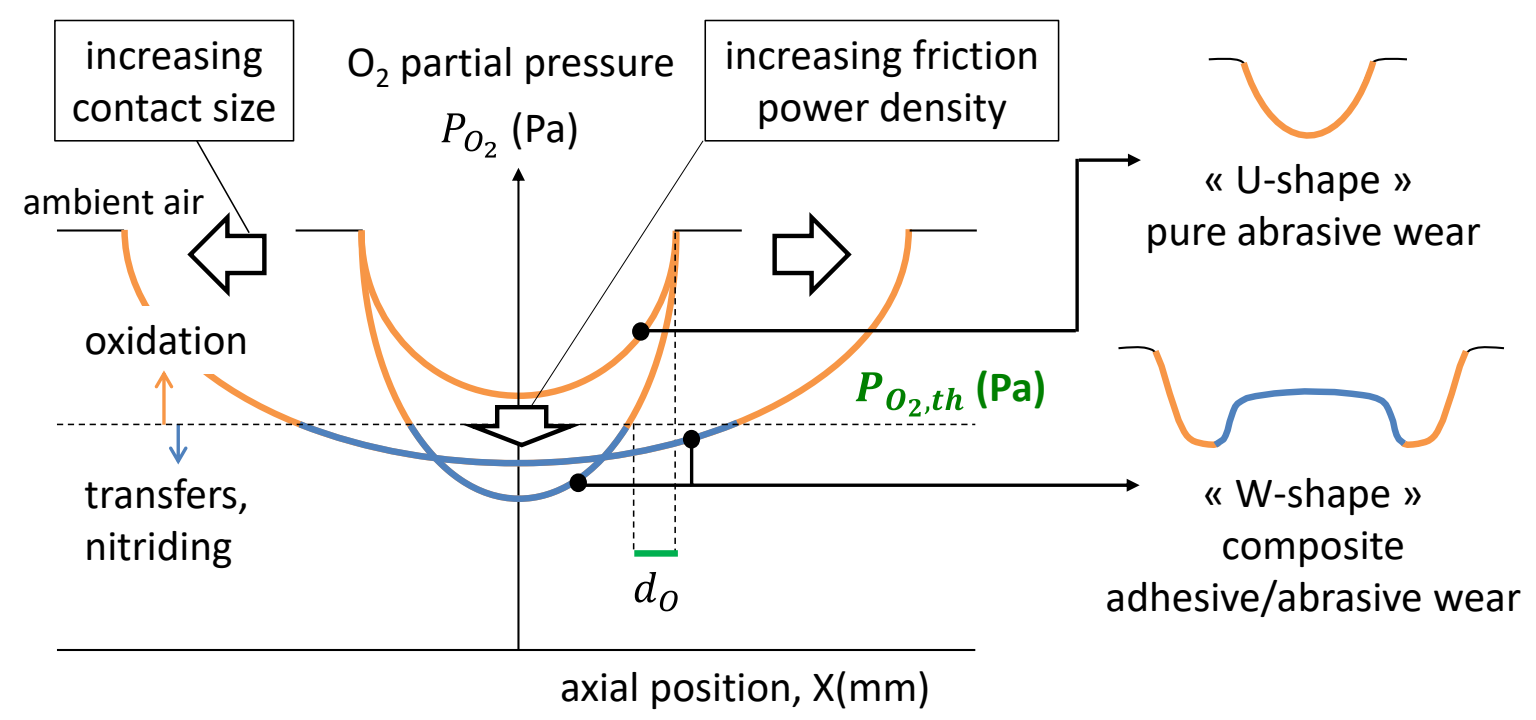

Fig. 7: Illustration of the Contact Oxygenation Concept: by considering the profile of $\mathrm{O}_{2}$ partial pressure within the fretted interface, a quantitative description of the adhesive and the abrasive wear in fretting wear interface can be considered [15].

The $P_{O_{2}}$ profiles depend on the contact configuration, contact size but above all on the contact loading (Fig. 7). Hence, the friction power density appears as a key parameter to express the reaction rate between $\mathrm{O}_{2}$ and the metal surface. The faster is the oxidation rate, the faster is the reduction of $P_{\mathrm{O}_{2}}$ and finally the larger is the inner adhesive wear domain. The Contact Oxygenation Concept was quantified and formalized by Baydoun et al. [16] by considering an Advection-Dispersion-reaction (ADR) model. This ADR model developed for a 3D contact configuration (i.e. 2D interface description) is fully detailed in [16]. However, in the current study, the ADR model will be transposed to a 2D contact configuration (i.e. 1D interface description) and will be briefly reminded in this section. In this model, the third body layer is assumed as a porous compact powdery dry structure traversed by atmospheric gases specifically di-oxygen and di-nitrogen. The advection-dispersion-reaction (ADR) continuity equation of a gas component " $i$ " is as follows:

$a \frac{d P_{i}}{d t}=-\nabla \cdot\left(J_{i}\right)+R_{i}=-\nabla \cdot\left(J_{a, i}+J_{d, i}\right)+R_{i}=-\nabla \cdot\left(-D_{i} \nabla P_{i}+v P_{i}\right)+R_{i}$

Such that, for a gas component " $i$ ", $P_{i}$ is the gas partial pressure ( $\left.\mathrm{Pa}\right), R_{i}$ the reaction rate, $J_{i}$ the general molar flux, $J_{a, i}$ the advective flux, $J_{d, i}$ the dispersive flux, $D_{i}$ the dispersion coefficient, $a$ the debris bed porosity, $v$ the advection velocity of the gas mixture in the debris bed $(\mathrm{m} / \mathrm{s}), P$ the total pressure of the gas mixture. Other variables like $\mu_{v}$ the viscosity of the entire gas mixture $(\mathrm{Kg} / \mathrm{m} . \mathrm{s})$ (estimated using Wilke model [26]), $k$ the intrinsic permeability of the debris bed $\left(\mathrm{m}^{2}\right)$ (computed using Carman-Kozeny equation [27]), $d_{p}$ the average particle size in the debris bed must be also considered in this ADR simulation. 


\section{Advection contribution}

Advection is defined as the bulk motion of the whole gas mixture resulting from the gradients in the total pressure:

$J_{a, i}=v P_{i}$

Gas advection velocity " $v$ " is defined using Darcy's law as a function of the total pressure gradients:

$v=-\frac{k}{\mu_{v}} \cdot \nabla(P)=-\frac{k}{\mu_{v}} \cdot \nabla\left(\Sigma P_{i}\right)$

The determination of the viscosity $\left(\mu_{v}\right)$ and the intrinsic permeability $(k)$ of the interface is fully detailed in paper [16] and is related to the studied interface as shown in Table 2.

\section{Dispersion contribution}

Fick's law [28] is used to describe dispersion phenomenon by linking the dispersive flux of a gas component " $i$ " to the associated partial pressure gradients:

$J_{d, i}=-D_{i} \nabla P_{i}$

Two dispersion coefficients can be distinguished yielding the dispersion of a gas component " $i$ " $\left(D_{i}\right)$ [29]:

$D_{i}=D_{\text {mechanical mixing }}+D_{\text {diffusion }, i}$

$D_{\text {diffusion, } i}$ is the effective molecular diffusion term of dispersion describing the diffusive flux controlled by molecular diffusion. However, $D_{\text {mechanical mixing }}$ is the mechanical mixing term of dispersion which is solute-independent in contrary to $D_{\text {diffusion, } i}$ [29].

$D_{\text {diffusion }, i}$ is computed in Eq. 18 [29]:

$D_{\text {diffusion }, i}=\eta \cdot D_{i, m}$

Where $D_{i, m}$ is the diffusion coefficient [29] of a gas constituent " $i$ " in a homogeneous mixture of " $m$ " gases [26] and $\eta$ is the tortuosity which describes the diminution of the effective diffusion coefficient caused by the solid-phase that reduces the cross-sectional area available for diffusion [31]. The determination of these variables is detailed in [16] and the corresponding values are compiled in Table 2.

The mechanical mixing term of dispersion [29] is:

$D_{\text {mechanical mixing }}=\alpha_{L} \cdot|v|$

Where $\alpha_{L}$ is the longitudinal dispersivity of the gas mixture which can be empirically linked to the distance traversed by the gas (i.e. " $a_{w}$ "). Pickens and Grisak equation [32] is considered to describe $\alpha_{L}$ :

$\alpha_{L}=\frac{a_{w}}{10}$ 
However in our case, the contact length $a_{w}$ evolves with the surface wear extension of the studied 2D cylinder-on-flat contact. Therefore, after each $\mathrm{n}^{\text {th }}$ surface wear iteration a new longitudinal length $a_{w, n}$ of the simulated worn fretting scar is considered to complete the ADR analysis assuming that:

$\alpha_{L}=\frac{a_{w, n}}{10}$

\section{Particle size $\left(d_{p}\right)$}

Particle size which is required to estimate the porosity and the intrinsic permeability $(k)$ can be computed by SEM observation of the oxide debris powder. As the steel interface [16], Ti-6Al-4V powder debris layer suggested an average oxide debris size about $d_{p}=1 \mu \mathrm{m}$ diameter as observed in the previous fretting wear investigations [14]. Note that a sensitivity analysis detailed in [16] revealed that particle size ranging from 0.1 to $10 \mu \mathrm{m}$ does not influence significantly the prediction of the adhesive wear extension.

\section{Porosity of the debris bed $(a)$}

The porosity is an important parameter in the ADR model. Its estimation is quite complex and many parameters could affect this latter like the contact pressure and the particle size and shape [33]. However, due to the lack of information a constant value will be assumed. Hence, assuming cubically packed identical spherical particles, the proportion of the particle can be approximated by the ratio of the volume of the particle divided by the bigger cube which can contain the particle:

$$
r_{\text {solid }}=\frac{V_{\text {solid matrix }}}{V_{\text {bulk }}}
$$

Then, the porosity is determined by one minus this ratio:

$a=1-r_{\text {solid }}$

Considering the latter hypotheses, the porosity of the third body is assumed constant equal to $a=$ 0.48 .

\section{Threshold partial pressure $\left(\boldsymbol{P}_{O_{2}, t h}\right)$}

Oxidation of the metal surface occurs whenever the oxygen chemical potential in the environment is higher than the oxide chemical potential. Oxygen dissociation of the metal occurs below this equilibrium and above it oxidation occurs.

$\mathrm{Ti}_{(s)}+\mathrm{O}_{2(\mathrm{~g})} \leftrightharpoons \mathrm{TiO}_{2}(\mathrm{~s})$

For the homogeneous contact, only titanium will be considered. This metal displays a low standard enthalpy of oxide formation $\left(\mathrm{TiO}_{2}\right)$ around $-1000 \mathrm{~kJ} / \mathrm{mol}$ at $20{ }^{\circ} \mathrm{C}$ [34] which tends to promote oxidation even if the partial pressure of oxygen is very low. As a matter of fact, the threshold oxygen 
partial pressure of $\mathrm{TiO}_{2}$ dissociation at ambient temperature is almost equal to zero assuming the following relationship:

$P_{O_{2}, t h}=P^{a t m} \cdot \exp \left(\frac{\Delta_{r} H^{0}-T \Delta_{r} S^{0}}{R_{g} \times T}\right)$

Where $P^{a t m}$ is the ambient pressure, $\Delta_{r} H^{0}$ is the standard enthalpy of the reaction $(\mathrm{J} / \mathrm{mol}), \Delta_{r} S^{0}$ is the standard entropy of the reaction $(-185.3 \mathrm{~J} / \mathrm{k} / \mathrm{mol}[34]), T$ is the absolute temperature $(\mathrm{K})$ and finally $R_{g}$ is the gas constant $(\mathrm{J} / \mathrm{K} / \mathrm{mol})$. However, a value different from zero is more coherent to describe the transition of adhesive/abrasive wear in the fretting interfaces. In the frame of this investigation we consider a threshold partial pressure $P_{O_{2}, t h}$ equal to $0.1 \mathrm{~Pa}$ which was previously defined as a pertinent value by Iwabuchi et al. [17] studying the transition from pure abrasive to pure adhesive wear of a steel interface under controlled ambient air conditions. This rather high partial pressure could be interpreted assuming a competition between the thickness of the oxide layer formed between each sliding sequence and the corresponding material removal thickness by fretting wear. If the wear depth increment is thicker than the oxide layer formed, the wear process could shift from abrasive to adhesive wear response.

\section{Reaction contribution}

The titanium oxidation is the main process consuming the $\mathrm{O}_{2}$ molecules within the fretting interface. As a first approach, a linear decay of $\mathrm{O}_{2}$ is proposed whereby:

$R_{O_{2}}=-r_{O_{2}} \cdot P_{O_{2}}$

The $r_{\mathrm{O}_{2}}$ is the reaction rate coefficient of the oxidation reaction between the exposed metal and the interfacial $\mathrm{O}_{2}$ gas. This coefficient is influenced by many parameters including the tested materials, the generated oxides and the fretting conditions which play an important role. As matter of fact, increasing the dissipated friction power density in the fretted contact raises the oxidation reaction between the exposed metal and the interfacial $\mathrm{O}_{2}$ gas. As detailed previously, a key parameter dominating the surface metal reaction appears to be the friction power density factor (Eq. 27) which can be approximated as a function of the pressure condition so that :

$\varphi^{*}=\mu_{e} \times p \times \mathrm{v}=\mu_{e} \times p \times\left(4 \times \delta_{g} \times p \times f\right)$

To introduce a discrete formulation of the reaction term as a function of the local condition through the interface, the friction power density can be written as:

$\varphi^{*}(x)=\mu_{e} \times \delta_{\text {cumulated }}(x) \times p(x) \times f$ 
Where $\delta_{\text {cumulated }}(x)$ corresponds to the cumulated sliding at the $x$ position for one cycle, $p(x)$ is the normal pressure at $x$ position. Note that $\delta_{\text {cumulated }}$ is almost equal to $4 \times \delta_{g}$ for large sliding amplitude but at the contact center and for small sliding amplitude, significant differences can occur.

In a former work [16] the reaction $r_{\mathrm{O}_{2}}$ parameter was expressed as a power law function of the Archard power density $\left(\omega^{*}\right)$. However, knowing that the interfacial shear work is physically more representative than the Archard work (i.e. pressure work) to describe surface damage rates, the following reaction rate formulation is derived as a function the friction power density so that :

$r_{O_{2}}=\beta\left(\frac{\varphi^{*}}{\varphi_{r e f}^{*}}\right)^{\gamma}$

Note that the given formulation is equivalent to the Archard as $\mu_{e}$ is nearly constant which implies:

$\varphi^{*}=\mu_{e} \times \omega^{*}$

A key aspect of the model is the determination of $\beta\left(\mathrm{s}^{-1}\right)$ coefficient and $\gamma$ exponent. The flat-on-flat fretting wear methodology introduced in [16] was adopted for the studied homogeneous Ti-6Al-4V interface. The advantage of this flat-on-flat configuration is that the contact area does not increase with the surface wear and the contact pressure profile can be assumed constant and flat over the whole test duration. The calibration tests of Ti-6Al-4V interface were performed at ambient conditions of temperature $\left(25^{\circ} \mathrm{C}\right)$ and humidity $(\mathrm{RH}=40 \%)$ and the loading conditions are fretting cycles $\mathrm{N}=20000$ cycles, contact pressure $\mathrm{p}=100 \mathrm{MPa}$, sliding amplitude $\delta_{\mathrm{g}}= \pm 100 \mu \mathrm{m}$ and contact area $\mathrm{S}=25 \mathrm{~mm}^{2}\left(L_{x}=L_{y}=5 \mathrm{~mm}\right.$ ) (Fig. 8a). Finally, three sliding frequencies were investigated: 1,5 and $10 \mathrm{~Hz}$ which lead respectively to $\varphi^{*}=0.024,0.12$ and $0.24 \mathrm{~W} / \mathrm{mm}^{2}$ by assuming $\mu_{e}=0.6$.

$\varphi_{\text {ref }}^{*}$ is the reference friction power density at $\mathrm{f}=1 \mathrm{~Hz}, \mathrm{p}=100 \mathrm{MPa}$ (i.e. $\mathrm{F}_{\mathrm{N}}=2500 \mathrm{~N}$ ), $\delta_{\mathrm{g}}= \pm 100 \mu \mathrm{m}$, $\mathrm{N}=20000$ cycles, and $L_{x}=L_{y}=5 \mathrm{~mm}$ (i.e. $\mathrm{S}=25 \mathrm{~mm}^{2}$ ) and equals to $0.024 \mathrm{~W} / \mathrm{mm}^{2}$.

To determine $\beta$ coefficient and $\gamma$ exponent, the ADR model was calibrated so that the error between the experimental and the simulated $d_{O}$ abrasive length scale extension (Figs. 6 and 7) measured on the contact border (as illustrated in Fig. 8) is reduced. The best fitting was found for $\beta=218.64 \mathrm{~s}^{-1}$ and $\gamma=0.94$. Note that this parameter identification was done without considering nitriding process assuming that $R_{N_{2}}=0$. In fact, nitriding process was only observed in the inner adhesive zone when the interface is fully deprived of di-oxygen. Moreover, nitriding process was never observed in the lateral abrasive domains where only oxidation process was detected. Therefore, we can assume that only the contact oxygenation process is monitoring the partition between adhesive and abrasive wear domains. Fig. 9 illustrates the evolution of the oxidation reaction rate $r_{\mathrm{O}_{2}}$ extracted from the given ADR modelling as a function of the applied frequency. The analysis suggests that the reaction rate between $\mathrm{O}_{2}$ and Ti-6Al-4V is directly proportional to the applied frequency as detailed in [16]. 


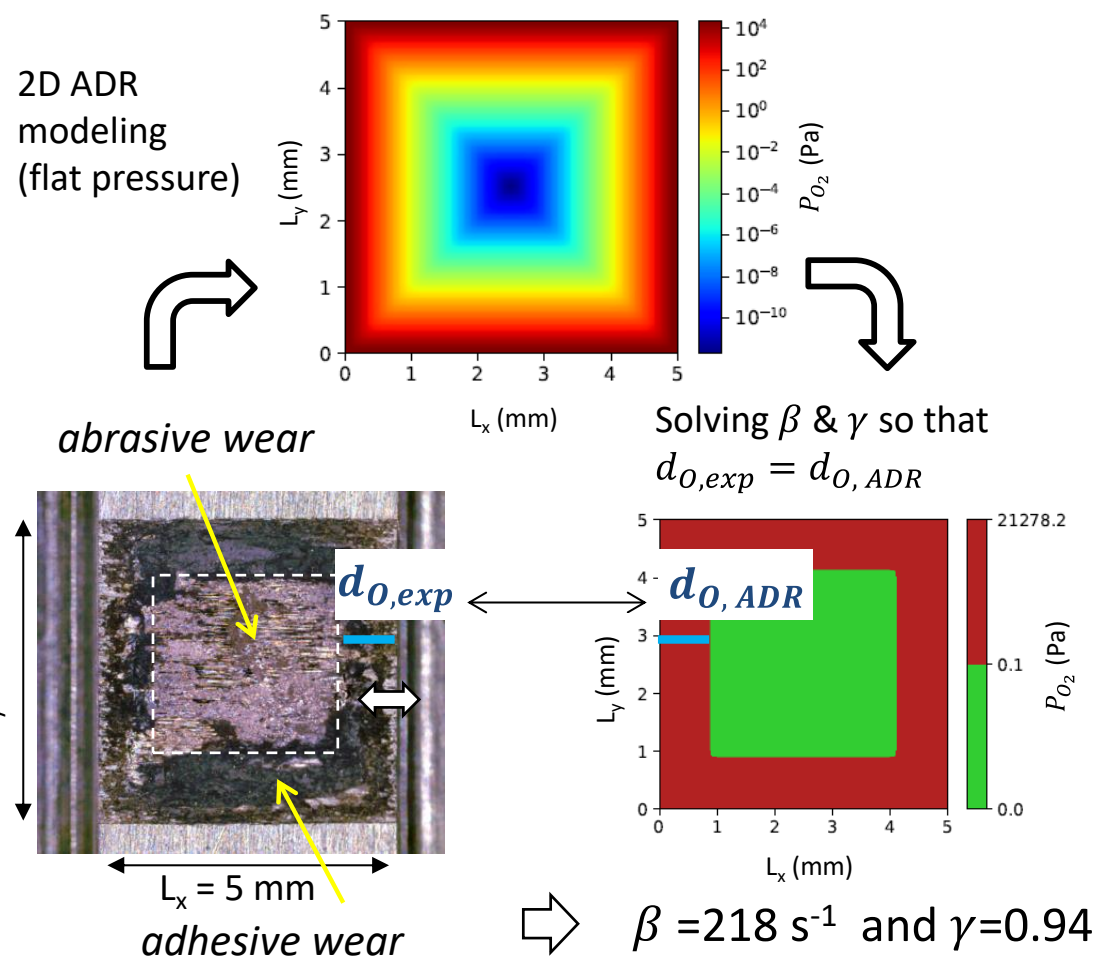

Fig. 8: Illustration of the flat-on-flat fretting methodology ( $N=20000$ cycles, $p=100 \mathrm{MPa}, \delta_{g}= \pm 100 \mu \mathrm{m}$, $f=5 \mathrm{~Hz}$ and $A=25 \mathrm{~mm}^{2}$ ) adopted from [16] to determine $\beta$ and $\gamma$ parameters of the reaction rate function (Eq. 29). Homogeneous flat-on-flat Ti6-Al-4V contacts were performed to quantify the extension of abrasive and adhesive wear domains measuring $d_{O, \text { exp }}$ from optical (or EDX) observations. Then 2D ADR simulations [16] (i.e. 3D contact) are performed assuming that $P_{O_{2}, \text { th }}$ (Ti$6 A l-4 V)=0.1 \mathrm{~Pa}$ in order to establish optimal $\beta$ and $\gamma$ parameters so that $d_{O, \exp }=d_{O, A D R}$.

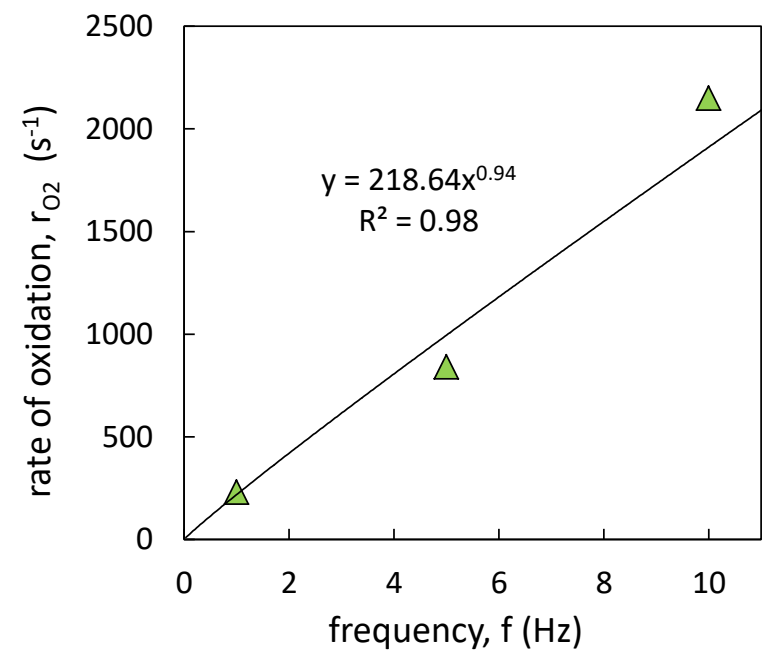

Fig. 9: Evolution of the reaction rate coefficient $r_{\mathrm{O}_{2}}$ extracted from the ADR analysis as function of the applied frequency. A linear evolution (i.e. $\gamma(T i-6 A l-4 V)=0.94 \sim 1$ ) is observed suggesting that the reaction rate of the Ti-6Al- $4 \mathrm{~V}$ is proportional to the applied frequency. 


\subsection{2 - Finite difference method}

The analytical solution of the ADR model could be possible if the problem was linear (advection, dispersion and reaction coefficients are constant), but in the studied situation, many parameters evolve in the contact due to surface wear and local contact loading fluctuations. Thus, the latter will be resolved numerically using the finite-difference method applied by Stein and co-authors [30]. Bilateral wear of the cylinder and the plane counterfaces as well as the third body layer is taken into account which can significantly influence the ADR modeling. To achieve such a physical description, the ADR model should consider not only the third body shape but also its varying diffusion properties. This aspect is very complex and therefore a 1D approach representative of the current 2D cylinder-on-flat configuration is chosen simplifying the hypotheses in many aspects. Thus, an equivalent diffusion through the third body is modeled. The contact length $L_{x}$ (for a contact area " $S=L_{x} . U$ " where $U$ is unit of depth model) is discretized into $n_{x}$ nodes between which there is a linear variation of the gas partial pressures. So, the continuity equation will be discretized such that contact length $L_{x}$ is divided into $p$ segments centered at the nodes:

$a_{(p)} \frac{d P_{i(p)}}{d t}=\frac{J_{i\left(p-\frac{1}{2}\right)^{-J}\left(p+\frac{1}{2}\right)}}{\Delta x}+R_{i}$

The time domain discretization is expressed as follows:

$\frac{P_{i(p)}^{j+1}-P_{i(p)}^{j}}{\Delta t}=\frac{J_{i\left(p-\frac{1}{2}\right)^{-J}}{ }_{i\left(p+\frac{1}{2}\right)}}{\Delta x \cdot a_{(p)}}+\frac{R_{i}}{a_{(p,)}}$

$P_{i(p)}^{j+1}=P_{i(p)}^{j}+\Delta t \cdot\left(\frac{J_{i\left(p-\frac{1}{2}\right)^{-J} i\left(p+\frac{1}{2}\right)}}{\Delta x \cdot a_{(p)}}+\frac{R_{i}}{a_{(p)}}\right)$

Then, we can define the function $f_{i(p)}^{j}$ which describes the evolution of the gas partial pressure:

$P_{i(p, q)}^{j+1}=P_{i(p)}^{j}+\Delta t . f_{i(p)}^{j}$

for $i \in[1, m], p \in\left[1, n_{x}\right], j \in\left[0, n_{t}\right]$

\section{Solution method}

An order 4 Runge-kutta method (RK4) is used to solve the partial differential equation of the ADR equation. By reducing the former 2D development [16] to the given 1D configuration, we get:

$\frac{d P_{i(p)}}{d t}=f_{i(p)}^{j}=f\left(t_{j}, P_{i(p)}^{j}\right)$

$P_{i(p)}^{j=0}=P_{i(p)}^{0}$

The four RK4 increments are calculated and then, for a time step " $j+1$ ", the partial pressure of gas component " $i$ " at a node " $p$ " is computed by summing the weighted average of the RK4 increments with the gas pressure at the former time step " $j$ ": 
$P_{i(p)}^{j+1}=P_{i(p)}^{j}+\frac{1}{6} \cdot\left(K_{1}+2 \cdot K_{2}+2 \cdot K_{3}+K_{4}\right)$

$t_{j+1}=t_{j}+\Delta t$

The steady state solution is obtained when the root mean square of the difference between the pressure profiles at consecutive time increments is below a convergence criterion $\varepsilon_{r}$.

$\sqrt{\frac{1}{n_{x}} \sum_{i=1}^{n_{x}}\left(P_{i}^{j+1}-P_{i}^{j}\right)^{2}}<\varepsilon_{r} \quad$ with $\quad \varepsilon_{r}=0.0001$

\section{3 - Global algorithm}

Table 2 compiles all the physical variables considered respectively for the mechanical friction energy surface wear modeling and the ADR tribo-chemical modeling. Fig. 10 displays the global algorithm of the simulation.

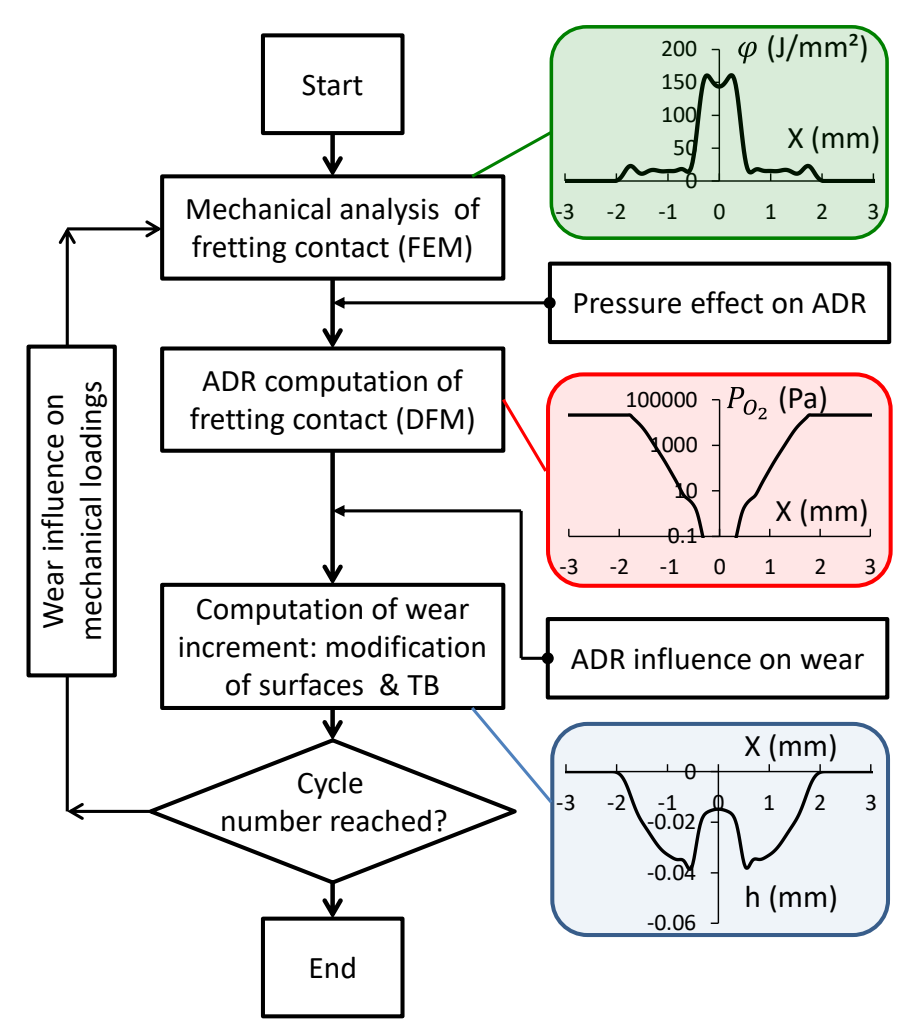

Fig. 10: Global algorithm of the proposed multiphysics WTO wear modeling combining friction energy (i.e. mechanical), third body simulation and ADR simulation of the contact oxygenation configuration (i.e. di-oxygen partial pressure profile within the interface).

First, all the geometrical, loading and material parameters are given in the script, and then a resolution of the mechanical surface is performed using the FE simulation for the first numerical iteration $n=1$. The model provides local contact loading variables like the sliding amplitude, the local pressure, the contact size, etc. These data are then extracted and prost-treated (Mathlab \& Python code) to compute the local friction energy and the local friction power densities. All these 
local loading variables are then transposed in the ADR modeling (Matlab code) to compute the reaction, advection and the dispersion terms as detailed previously. Once the ADR computations are performed, the partial pressure profile of the di-oxygen is extracted from the converged solution at the $j=$ final increment in order to determine the local friction energy coefficient depending on the local contact oxygenation condition.

Then, the model simulates a response with two local wear coefficients depending on the dioxygen partial pressure and taking into account the presence of the third body (tb), which implies that:

if $P_{O 2}(x) \geq P_{O 2, t h}, \alpha_{p / t b, n}(x)=\alpha_{p, a b}$ and $\alpha_{c / t b, n}(x)=\alpha_{c, a b}$

if $P_{O 2}(x)<P_{O 2, t h}, \alpha_{c / t b, n}(x)=\alpha_{c, a d}$ and $\alpha_{p / t b, n}(x)=\alpha_{p, a d}$

Following this step, surface wear and third body increments are computed and the plane, the cylinder and the third body profiles are updated. Then, the initial solutions of the ADR model during the second and the following increment are taken from the previous iteration:

$P_{O_{2}}^{j=0}$ from $n+1=P_{O_{2}}^{j=\text { final from } n}$

$P_{N_{2}}^{j=0 \text { from } n+1}=P_{N_{2}}^{j=\text { final from } n}$

This algorithm is not a converged solution of the current multiphysics problem but rather a steady state solution of the ADR model which is always reached at less than $0.1 \mathrm{~s}$. This duration is shorter than the fretting cycle time which appears to be $0.2 \mathrm{~s}$ justifying in turn this successive approach. Finally, the simulation loops until the target number of fretting cycles is reached. This global modeling combining Wear (friction energy), the Third body and the contact Oxygenation concepts is presently abbreviated as WTO.

Table 2: Compilation of all the physical variables considered for the WTO (Wear, Third body and Oxygenation) modeling combining respectively the mechanical friction energy surface wear modeling and the ADR tribo-chemical modeling.

\begin{tabular}{|l|l|l|l|l|l|}
\hline $\begin{array}{l}\text { Air } \\
\text { condition }\end{array}$ & $\mathrm{T}=25^{\circ} \mathrm{C}=298^{\circ} \mathrm{K}$ & $\mathrm{P}=1 \mathrm{~atm}=101325 \mathrm{~Pa}$ & $\mathrm{R}_{\mathrm{g}}=8.314 \mathrm{~J} / \mathrm{K} . \mathrm{mol}$ & $P_{\mathrm{O}_{2}}=21278 \mathrm{~Pa}$ & $P_{\mathrm{N}_{2}}=80046 \mathrm{~Pa}$ \\
\hline $\begin{array}{l}\text { Gas } \\
\text { properties }\end{array}$ & Di-oxygen & $T_{c, O_{2}}=154.4 \mathrm{~K}$ & $\begin{array}{l}V_{c, O_{2}} \\
=0.08 \mathrm{~m}^{3} / \mathrm{kmol}\end{array}$ & $M_{\mathrm{O}_{2}}=32 \mathrm{~g} / \mathrm{mol}$ & $\begin{array}{l}\mu_{v, O_{2}} \\
=20.810^{-6} \mathrm{~kg} / \mathrm{m} . \mathrm{s}\end{array}$ \\
\hline $\begin{array}{l}\text { Reaction } \\
\text { properties }\end{array}$ & $\begin{array}{l}\text { Oxygenation } \\
\text { reaction }\end{array}$ & $\beta=218.64$ & $\begin{array}{l}V_{c, N_{2}} \\
=0.089 \mathrm{~m}^{3} / \mathrm{kmol}\end{array}$ & $M_{O_{2}}=28 \mathrm{~g} / \mathrm{mol}$ & $\begin{array}{l}\mu_{v, O_{2}} \\
=17.910^{-6} \mathrm{~kg} / \mathrm{m} . \mathrm{s}\end{array}$ \\
\hline $\begin{array}{l}\text { Third body } \\
\text { properties }\end{array}$ & $E=100 \mathrm{GPa}$ & $\begin{array}{l}\text { Coef. of Poisson } \\
\mathrm{v}=0.3\end{array}$ & $d_{p}=1 \mu \mathrm{m}$ & $\begin{array}{l}\varphi_{r e f}^{*} \\
=0.024 \mathrm{~W} / \mathrm{mm}^{2}\end{array}$ & $P_{O 2, t h}=0.1 \mathrm{~Pa}$ \\
\hline First bodies & $E=119 \mathrm{GPa}$ & Coef. of Poisson & & & \\
\hline
\end{tabular}




\begin{tabular}{|l|l|l|l|l|l|}
\hline & & $\mathrm{v}=0.287$ & & & \\
\hline $\begin{array}{l}\text { Wear } \\
\text { properties }\end{array}$ & Cylinder & $\begin{array}{l}\alpha_{c, a b} \\
=4.110^{-4} \mathrm{~mm}^{3} / \mathrm{J}\end{array}$ & $\begin{array}{l}\alpha_{c, a d} \\
=1.010^{-5} \mathrm{~mm}^{3} / \mathrm{J}\end{array}$ & & \\
\hline & Plane & $\begin{array}{l}\alpha_{p, a b} \\
=5.110^{-4} \mathrm{~mm}^{3} / \mathrm{J}\end{array}$ & $\begin{array}{l}\alpha_{p, a d} \\
=1.010^{-4} \mathrm{~mm}^{3} / \mathrm{J}\end{array}$ & & \\
\hline & Third body & $\gamma_{t b}=0.85$ & & & \\
\hline $\begin{array}{l}\text { Numerical } \\
\text { parameters }\end{array}$ & $\begin{array}{l}\text { space discr. } \\
=40 \mu \mathrm{m}\end{array}$ & time discr. $=810^{-5} \mathrm{~s}$ & $\varepsilon_{r}=110^{-4}$ & $\begin{array}{l}\beta_{A, n} \text { adjusted to achieve a } 3 \mu \mathrm{m} \\
\text { increment of wear }\end{array}$ \\
\hline
\end{tabular}

\section{Results}

\subsection{Comparison between predicted and experimental wear profiles}

Fig. 11 compares both the experimental and the simulated wear profiles (WTO) as a function of the applied sliding frequency. As detailed in [15], by rising the frequency, the friction power density increases promoting the transition from deeper U-shape abrasive fretting wear scar toward a thinner $\mathrm{W}$-shape abrasive-adhesive fretting scar. The transition from U-shape to $\mathrm{W}$-Shape structure is observed here around $f=1 \mathrm{~Hz}$ which is well predicted by the model. Besides, increasing the frequency and the related friction work density induces a reduction of the global wear volume (i.e. worn surface measured below the base line). This tendency is again well predicted by the model by simulating the extension of the inner adhesive wear domain. Indeed, the larger is the inner adhesive domain, the larger is the relative contribution of the lower adhesive $\alpha_{p, a d}$ wear coefficient and consequently the lower is the global wear volume extension. Finally, by reducing the wear rate coefficient in the inner part of the contact, the extension of the adhesive wear domain promotes a sharp reduction of the maximum wear depth which is also translated on the lateral sides where abrasive wear processes are still operating. This tendency is also captured well by the proposed WTO approach. 

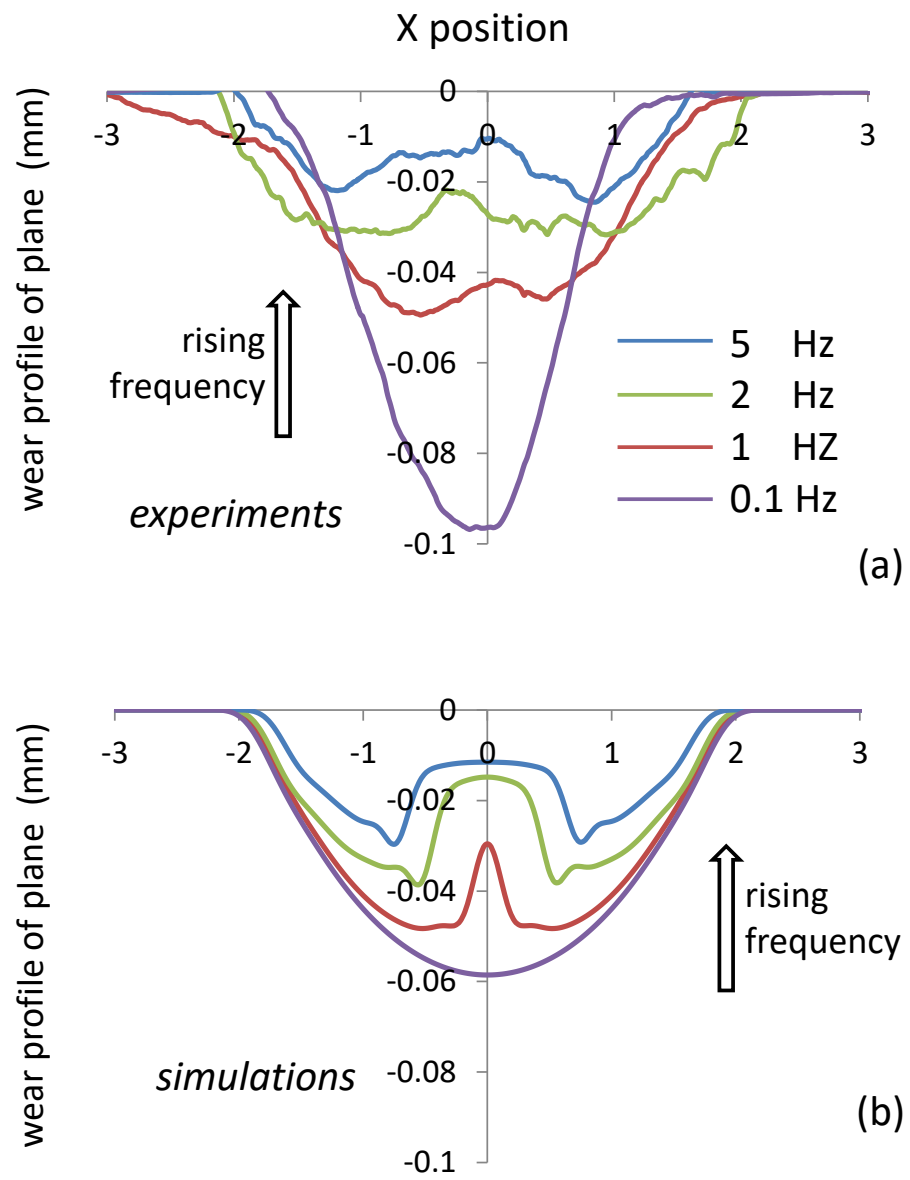

Fig. 11: Evolution of the wear profiles of the plane as a function of the applied sliding frequency (Ti-

$6 A L-4 V$ cylinder-on-flat interface, $R=80 \mathrm{~mm}, F_{n, L}=1066 \mathrm{~N} / \mathrm{mm}, \delta_{g}^{*}= \pm 75 \mu \mathrm{m}, \mathrm{N}=5000$ cycles): (a) experiments ; (b) simulations (Wear (friction energy) - Third body - contact Oxygenation modeling (i.e. WTO)) (simulation condition: Table 2).

Fig. 12 provides a more detailed comparison of the plane, cylinder and the total wear profiles as a function of the applied sliding frequency. The coupled approach of wear, third body and the ADR simulation of the contact oxygenation condition allows for the first time to predict both the U-shape and the W-shape fretting scars depending on the sliding frequency applied. Comparison between the experimental and the simulated wear profiles at $\mathrm{f}=0.1 \mathrm{~Hz}$, where pure abrasive wear is operating, displays however some discrepancies. 
$0.1 \mathrm{~Hz}$
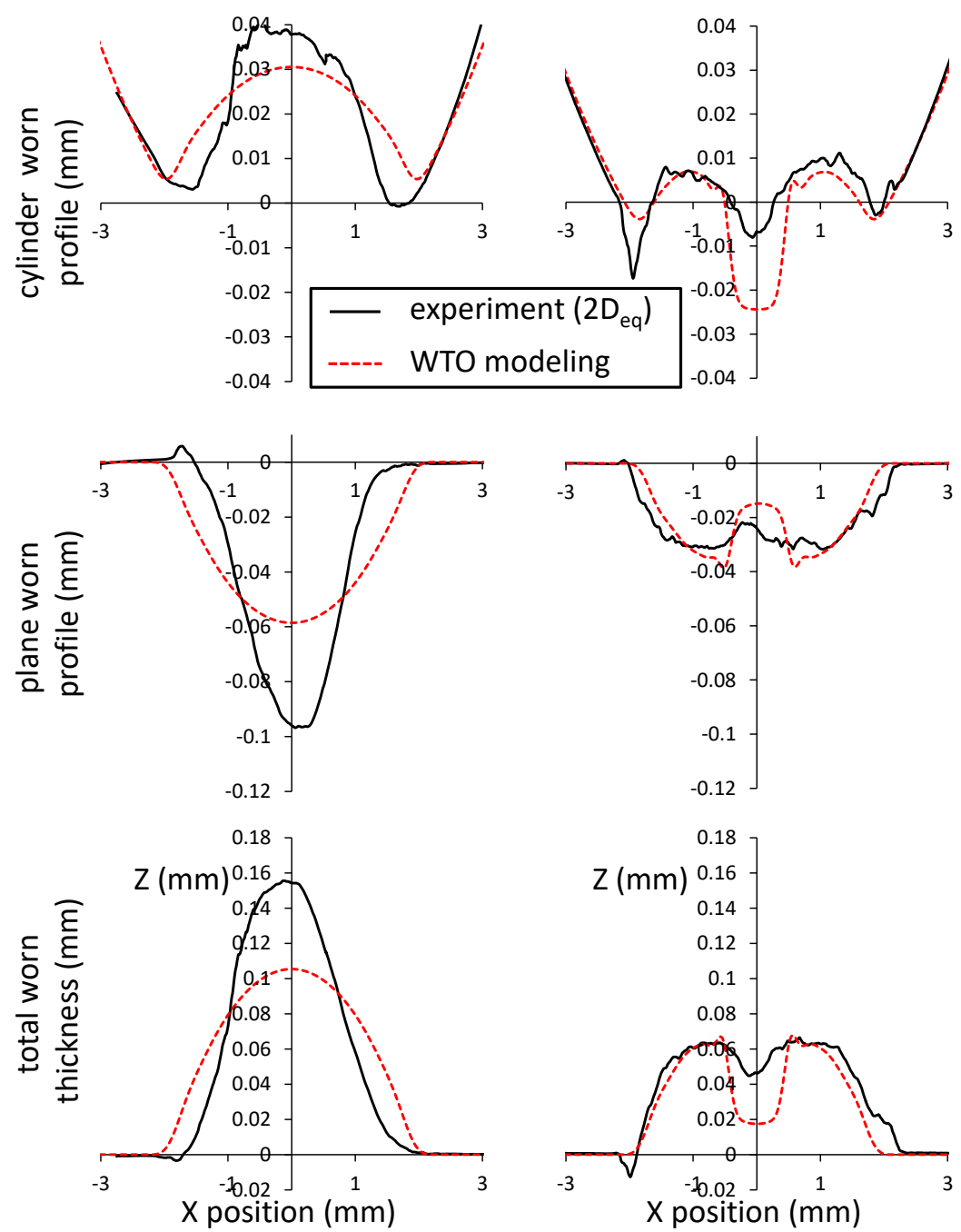

$2 \mathrm{~Hz}$
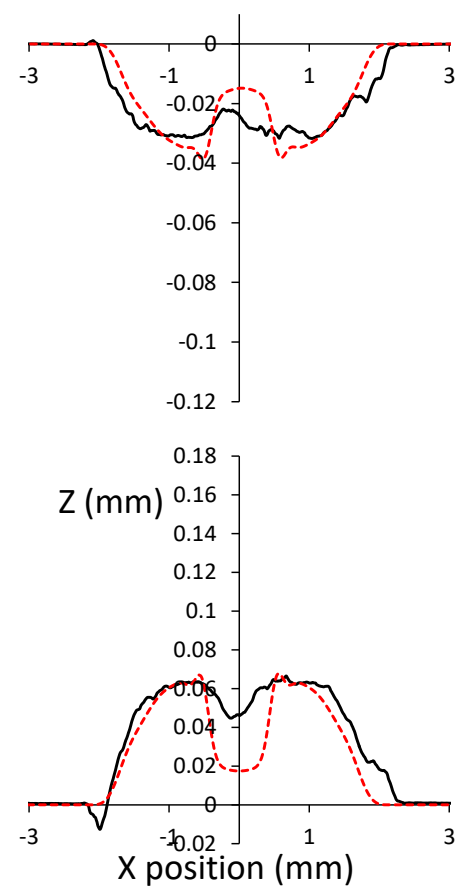

$5 \mathrm{~Hz}$
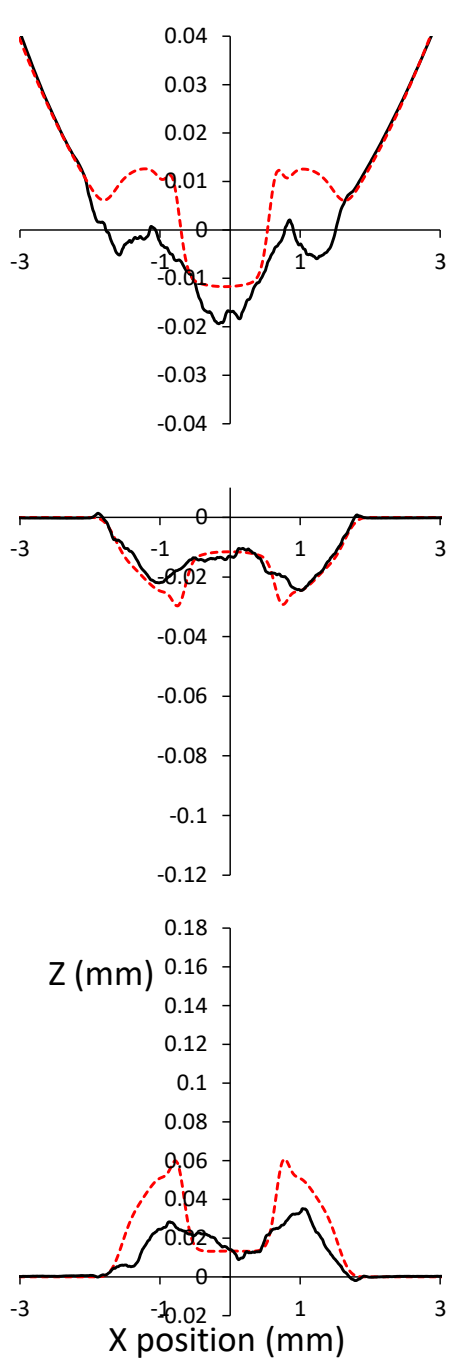

Fig. 12: Comparison between the simulated (i.e. given Wear (friction energy) - Third body - contact Oxygenation modeling (WTO)) and the experimental wear profiles and the third-body layer thickness as a function of the applied frequency (experimental conditions: Ti-6AL-4V cylinder-on-flat interface, $R=80 \mathrm{~mm}, F_{n, L}=1066 \mathrm{~N} / \mathrm{mm}, \delta_{g}^{*}= \pm 75 \mu \mathrm{m}, \mathrm{N}=5000$ cycles), (Simulation parameters: Table 2).

The U-shape morphology is well predicted although the simulations tend to overestimate the lateral wear extension and underestimate the maximum wear depth. This is not due to a misestimation of the global wear rate coefficient as the total worn surface (i.e. wear volume) is correctly estimated. However, this could be rather explained by the coarse approximation of the third body conversion factor which is presently assumed constant in time and space distribution (i.e. $\gamma_{t b}(x)=0.85$ ). Previous developments suggested that better U-shape fretting scar predictions can be achieved using an elliptic description of the $\gamma_{t b}(x)$ function inducing thicker third body layer in the central part of the contact. Regarding the higher frequencies $f=2$ and $5 \mathrm{~Hz}$, the correlation between the simulated 
and the experimental $2 \mathrm{D}_{\text {eq }}$ profiles is better. Again, the model is able to capture the W-shape of the fretting scar but also to predict the lateral extension of the material hit in the contact center. The correlation between the experiments and the numerical simulations is rather good for the test at $\mathrm{f}=2$ $\mathrm{Hz}$ and is slightly more dispersed for $\mathrm{f}=5 \mathrm{~Hz}$, particularly for the worn cylinder profile. As mentioned previously, material transfers from the plane toward the cylinder surface are usually activated at the beginning of the test. This incipient transfer phenomenon is not included in the model and can explain this discrepancy. To quantify the performance of this new multiphysics WTO surface wear approach, two error indexes regarding the prediction of the maximum wear depth and the axial localization of this latter are computed as follows:

$h_{\text {max }} \%=\left|\frac{h_{\text {max }, \text { exp }}-h_{\text {max }, \text { pred }}}{h_{\text {max }, \text { exp }}}\right| \times 100$

$X_{h_{\text {max }}} \%=\left|\frac{X_{h_{\text {max }}, e_{0}-X_{h_{\text {max }}, p r e d}}}{X_{h_{\text {max }}, \text { exp }}}\right| \times 100$

The given multiphysics approach (WTO) is compared here versus the equivalent plain friction energy wear approach taking into account the third body but not the contact oxygenation process (abbreviated by WT).
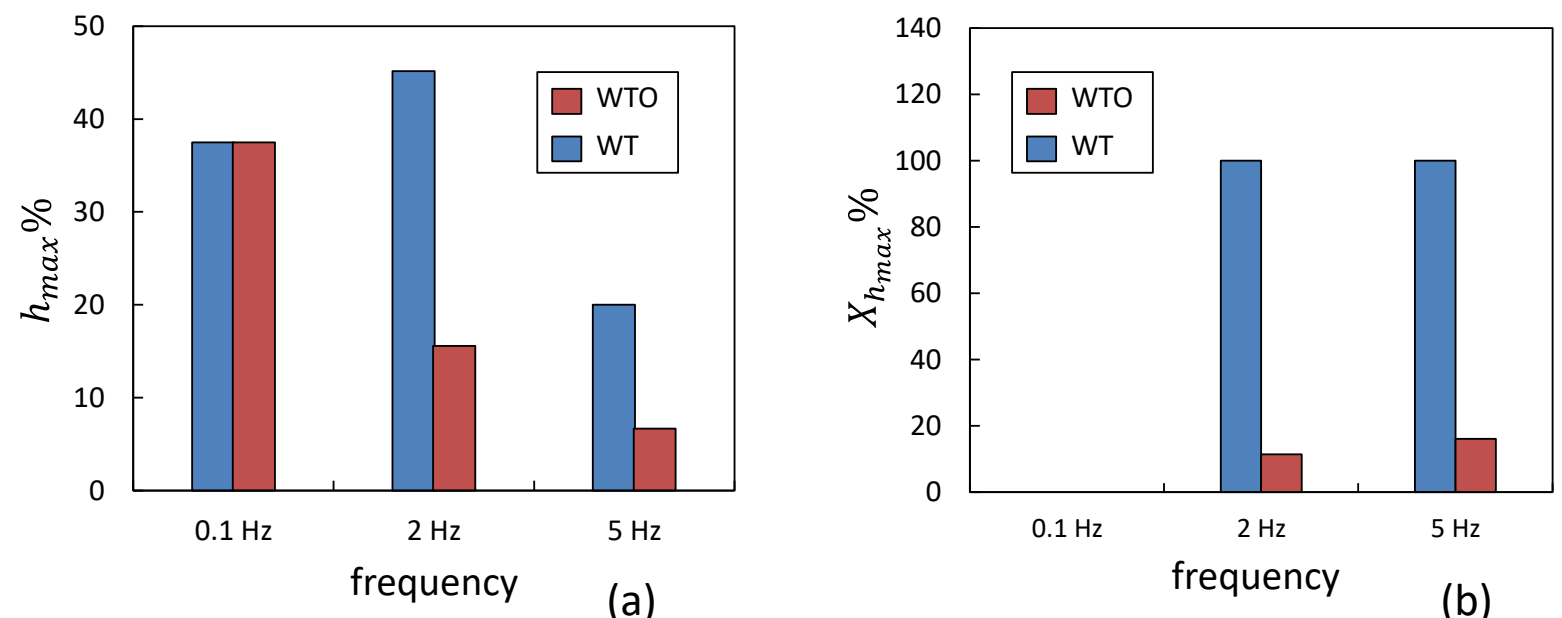

Fig. 13: Comparison between the given multiphysics Wear (friction energy) - Third body - contact Oxygenation modeling (WTO) and the same approach without considering the contact oxygenation (WT): (a) relative error regarding the experimental maximum wear depth (b) relative error regarding the experimental lateral position of the maximum wear depth (experimental conditions: Ti-6AL-4V cylinder-on-flat interface, $R=80 \mathrm{~mm}, F_{n, L}=1066 \mathrm{~N} / \mathrm{mm}, \delta_{g}^{*}= \pm 75 \mu \mathrm{m}, \mathrm{N}=5000$ cycles), (Simulation parameters: Table 2).

Both the maximum wear depth $\left(h_{\max } \%\right)$ and the contact location $\left(X_{h_{\max }} \%\right)$ relative errors of the WTO and the plain WT simulations are compared in Fig. 13. As expected, for the U-shape configuration (i.e. $\mathrm{f}=0.1 \mathrm{~Hz}$ ) the two approaches led to similar results as no adhesive wear is 
activated. The two models predict well the extension of the contact so that $X_{h_{\max }} \%=0$. As discussed previously the maximum wear depth prediction is however quite dispersive (i.e. $h_{\max } \%=$ $35 \%$ ) due to a misestimation of the third body profile induced by a coarse approximation of the third body conversion factor distribution. However, a significant difference between WTO and WT strategies is observed when adhesive wear process is activated in the inner part of the contact inducing $\mathrm{W}$-shape structure (i.e. $\mathrm{f}>1 \mathrm{~Hz}$ ). The plain WT approach still considers a homogeneous wear approach leading to U-shape fretting scar morphology. The localization of the maximum wear is still predicted at the center of the contact which is fully inconsistent and leads to a maximum error $X_{h_{\max }} \%=100 \%$ (Fig. 13b). A similar discrepancy is also observed regarding the maximum wear depth prediction with $h_{\max } \%=45 \%$ and $20 \%$ for $\mathrm{f}=2 \mathrm{~Hz}$ and $5 \mathrm{~Hz}$ respectively. By contrast, the WTO approach highly improves the prediction. The maximum error, regarding the wear depth prediction, falls below $15 \%$ when $\mathrm{f}=2 \mathrm{~Hz}$ and below $5 \%$ when $\mathrm{f}=5 \mathrm{~Hz}$. Moreover, by considering adhesive wear processes and transfer phenomena, the WTO approach better predicts the location of the maximum

wear depth decreasing the $X_{h_{\max }} \%$ index error below $20 \%$. Hence, despite model simplification, the given WTO surface wear modeling appears as a very convenient strategy to predict fretting wear profiles and maximum fretting wear depths. It is important to underline that the given friction energy wear description was calibrated using a restricted set of Ti6Al-4V fretting wear tests whereas the ADR parameters related to the Contact Oxygenation Concept were established from literature or extracted from few crossed flat-on-flat test conditions very different from the studied interface which indirectly support the stability of the proposal.

\subsection{Modeling the global energy wear coefficient as a function of the frequency}

Fig. 14 plots the evolution of the energy wear coefficients of the global interface predicted by the WTO modeling as a function of the applied frequency. Asymptotic decreasing evolutions are observed which can be approximated using the exponential function (Eq. 4) adjusting in consequence the coefficient of the law (Table 1). 


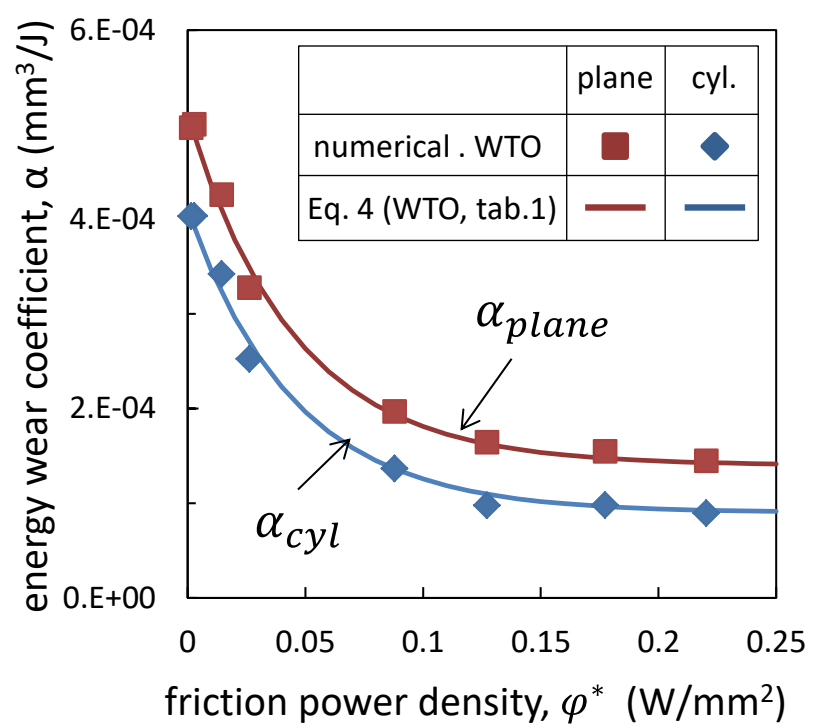

Fig. 14: Evolution of the friction energy wear coefficients predicted by the WTO as a function of the friction power density by varying the sliding frequency: numerical computation of the WTO model and the exponential approximation using Eq.4 (Table 1, WTO) (Ti-6AL-4V cylinder-on-flat interface, $R=80$ $\mathrm{mm}, F_{n, L}=1066 \mathrm{~N} / \mathrm{mm}, \delta_{g}^{*}= \pm 75 \mu \mathrm{m}, \mathrm{N}=5000$ cycles, f varying from 0.1 to $10 \mathrm{~Hz}$ ).

Using this exponential approximation both the experimental and the WTO predictions are compared in Fig. 15. Hence, despite its simplicity and the fact that only two intrinsic abrasive and adhesive energy wear coefficients are considered depending if at the position $x$ the contact is oxygenated or not (Eq. 41), a good prediction is provided by the WTO modeling. The asymptotic decreasing evolutions are well described and the asymptotic value of the equivalent wear coefficient of the plane counterface is rather well predicted. 


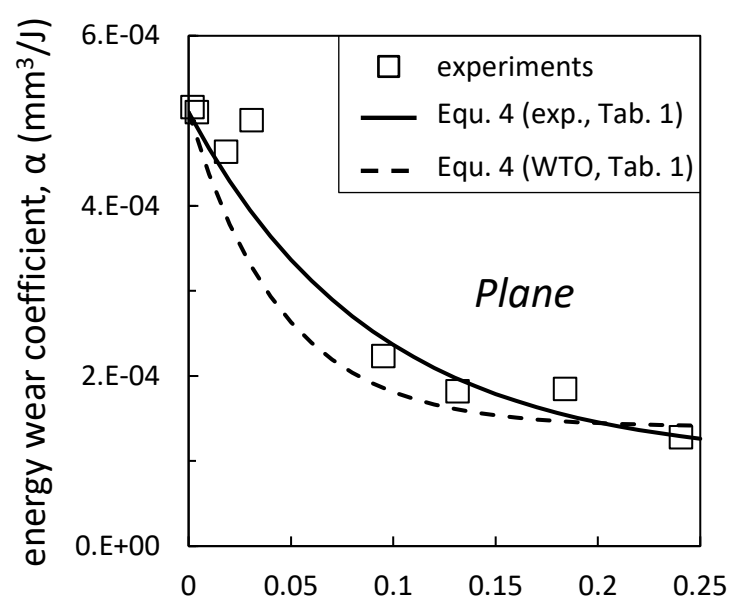

friction power density, $\varphi^{*}\left(\mathrm{~W} / \mathrm{mm}^{2}\right)$

(a)

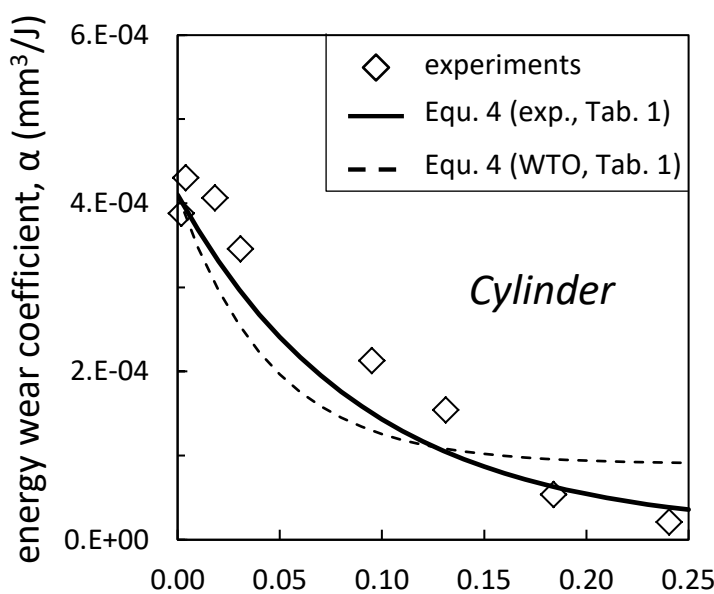

friction power density, $\varphi^{*}\left(\mathrm{~W} / \mathrm{mm}^{2}\right)$

Fig. 15: Evolution of the energy wear coefficient as a function of the applied frequency for the plane (a) and the cylinder counterparts (b): comparison between the experiments and the best fitting (Eq. 4) of the experiments and the WTO simulations (Table 1) (Ti-6AL-4V cylinder-on-flat interface, $R=80$ $\mathrm{mm}, F_{n, L}=1066 \mathrm{~N} / \mathrm{mm}, \delta_{g}^{*}= \pm 75 \mu \mathrm{m}, \mathrm{N}=5000$ cycles, f varying from 0.1 to $10 \mathrm{~Hz}$ ).

However, a significant discrepancy can be discerned particularly for the cylinder counterface. Again, this can be explained by the initial material transfer from the plane toward the cylinder counterface which cannot be considered by the given WTO modeling. Besides, it is interesting to note that the WTO overestimates the reduction of the global energy wear coefficient for the low and medium frequency conditions (i.e. between 0 and $0.1 \mathrm{~W} / \mathrm{mm}^{2}$ friction power conditions). This tendency can be explained regarding the porosity parameter. Indeed, in the model a single porosity coefficient is considered. Yet, it can be intuited that depending on the third body compaction and the contact pressure condition, the porosity of the debris layer can change. Hence, a powder debris layer induced by abrasive wear is expected to provide a higher porosity than the compacted third body generated within the adhesive domain. Therefore, it could be assumed that low and medium friction power conditions will promote, by favoring powdery abrasive third-body structure, a higher porosity coefficient as well as a larger extension of the abrasion zone. Finally a higher wear coefficient than predicted by the WTO simulation is observed. Hence, in addition to optimizing the third body conversion factor to better predict the wear profiles, this quantitative comparison with the experiments suggests that a variable porosity coefficient depending on the nature of the third body layer must be considered in the future development of the WTO approach. However, this first approach, which provides an a priori prediction of the fretting wear rate evolution depending on 
sliding frequency, appears as very interesting strategy to model the very complex processes involved in the fretting wear.

\section{5 - Discussion}

The former analysis confirms the capacity of the friction energy-contact oxygenation modeling (i.e. WTO modeling) to predict fretting wear profiles from pure abrasive to composite adhesive-abrasive wear conditions. The model could be improved in many aspects by better considering the third body evolution or introducing more elaborated description of the porous debris. However, despite the simplifications made, this model provides rather good predictions.

\subsection{Dynamic analysis of the fretting wear interface}

One advantage of this WTO approach is the possibility to investigate separately the effect of the loading or ambient conditions. Fig. 16 displays the computed $\mathrm{O}_{2}$ partial pressure profiles " $\mathrm{P}_{\mathrm{O}_{2}}(x)$ ", the surface wear profiles on both the plane and the cylinder counterparts, the resulting third body thickness and finally the friction energy density profiles which in fact nearly correspond to the contact pressure profile such that:

$p(x) \approx \frac{\varphi(x)}{4 \times \delta_{g} \times \mu_{e}}$

Focusing on the lowest frequency condition $(\mathrm{f}=0.1 \mathrm{~Hz})$, the partial pressure $P_{\mathrm{O}_{2}}(x)$ never underpasses the $P_{O 2, t h}$ threshold value leading to a homogeneous abrasive wear process over the whole fretted interfaces. Hence, a constant abrasive wear rate coefficient (i.e. $\alpha(x)=\alpha_{a b}$ ) is assumed over the whole fretted interface, promoting homogeneous elliptical wear profiles on both the plane and the cylinder surfaces. This promotes a bell-shaped third body layer which is directly proportional to the total wear profile such that the constant conversion factor is equal to $\gamma(x)=$ 0.85 . As expected, because a single abrasive wear process is activated, the wear profiles remain continuous (i.e. U-shaped structure) as the friction energy profiles (i.e. pressure profiles) display a continuous evolution from an initial Hertzian toward an almost flat distribution. The surface wear process observed for $\mathrm{f}=2$ and $5 \mathrm{~Hz}$, is much more complex. The di-oxygen partial pressure profile displays a fast drop from the beginning of the test such that a significant part of the inner fretted interface remains below the $P_{O_{2, t h}}$ oxygenation. Adhesive wear is activated in this domain whereas abrasive wear operates on the lateral zones. 

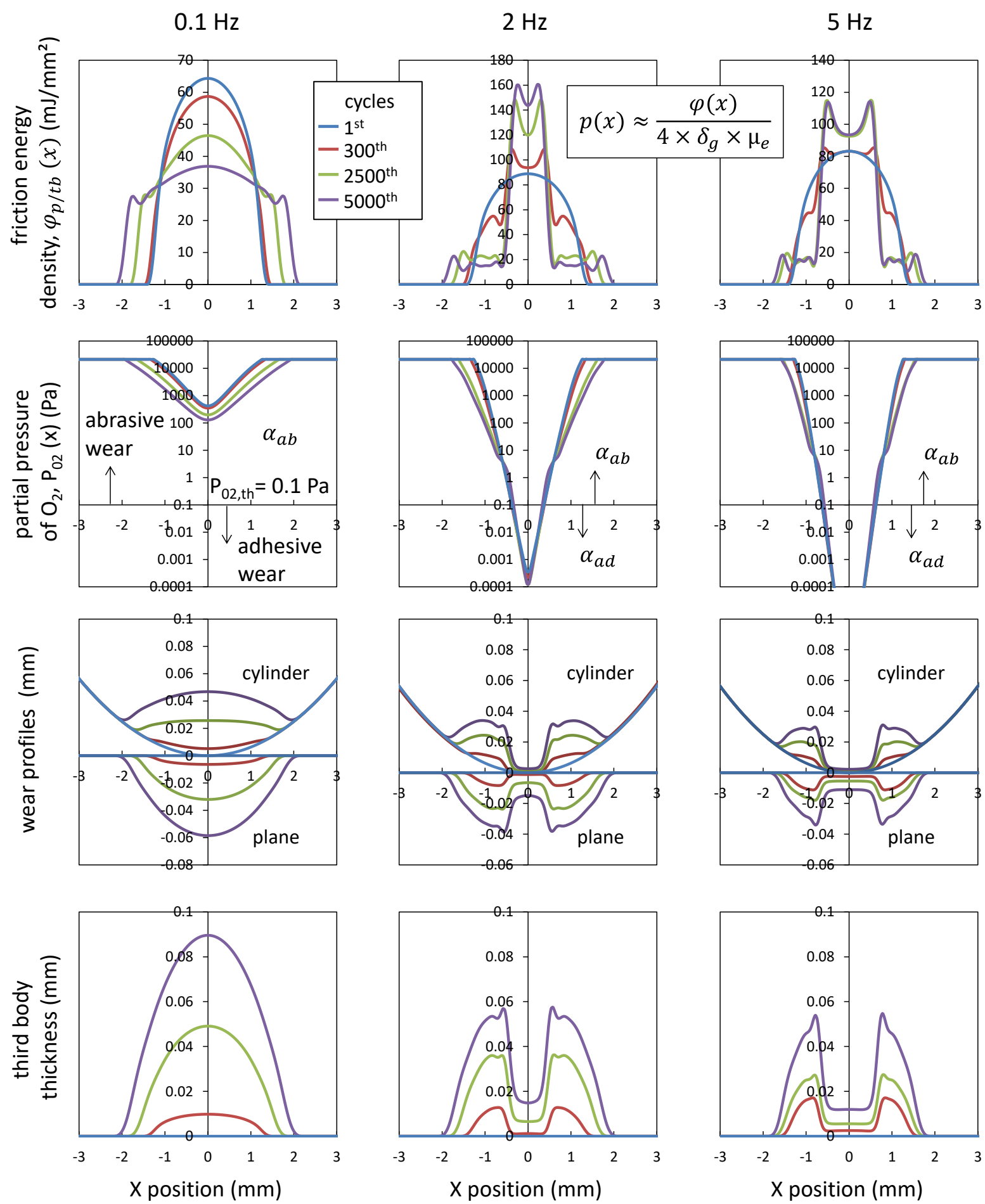

Fig. 16: Multi-physics simulation (WTO) of the evolution of the friction energy profiles (i.e. the related contact pressure), di-oxygen partial pressure profiles, plane and cylinder worn profiles and debris layer thickness profiles as a function of the applied sliding frequency (conditions: Ti-6AL-4V cylinderon-flat interface, $R=80 \mathrm{~mm}, F_{n, L}=1066 \mathrm{~N} / \mathrm{mm}, \delta_{g}^{*}= \pm 75 \mu \mathrm{m}, \mathrm{N}=5000$ cycles), (Simulation parameters: Table 2). 
This induces a sharp discontinuity of the local wear coefficient within the interface (i.e. $\alpha_{p, a b} / \alpha_{p, a d}>$ 4.5 and $\alpha_{c, a b} / \alpha_{c, a d}>8$ ) promoting wear rate fluctuations and surface profile discontinuities. The maximum wear depths are translated toward the lateral sides whereas a minimum wear depth is observed in the inner "adhesive" domain. This discontinuous response leads to the typical the Wshape fretting scar structure. This effect is even amplified for the cylinder counterpart due to the quasi-negligible adhesive wear rate coefficient estimated for this counterpart (i.e. $\alpha_{c, a d}=1.010^{-5}$ $\left.\mathrm{mm}^{3} / \mathrm{J} \approx 0.025 \alpha_{c, a b}\right)$.

\subsection{Long term evolution of the fretting scar morphology}

To evaluate the long term stability of the composite adhesive/abrasive wear interface, WTO computations were extended up to 80000 fretting cycles. Fig. 17 plots the evolution of the worn contact radius $a_{w}$ and the adhesive domain radius $a_{a d}$ as function of the fretting cycles number for the sliding frequencies $f=0.1,2$ and $5 \mathrm{~Hz}$. Note that the evolution of "oxygen distance $d_{o}$ " can also be extrapolated such that:

$d_{o}=a_{w}-a_{a d}$

For pure abrasive wear condition $(f=0.1 \mathrm{~Hz})$, adhesive wear is never activated $\left(a_{a d}=0\right)$ and simulations confirm a fast rising of the worn contact radius. Alternatively, by increasing the friction power density (i.e. sliding frequency), adhesive wear occurs such that the larger the sliding frequency, the larger the inner adhesive domain and the smaller the worn contact radius extension. This time analysis is quite interesting because it suggests that the initial adhesive domain smoothly decreases and then rises again but very smoothly after a few thousand fretting cycles. In fact, a quasi-constant evolution can be considered for $a_{a d}$ whereas the worn contact size $a_{w}$ continuously extends although at a smaller rate than for the pure abrasive "U-shaped" condition (i.e. $f=0.1 \mathrm{~Hz}$ ). These simulations propose that even for the composite "W-shape" interface, the worn area increase is mainly driven by the lateral extension of the abrasive wear domain toward the external part of the contact. Hence, after these computations, when an adhesive wear domain is generated, this latter is maintained whatever the global wear extension. Reversely, when pure abrasive wear is activated, the interface never evolves toward a composite adhesive/abrasive wear interface at least for the studied loading conditions. In fact, more advanced and longer simulations should be undertaken to clarify this aspect. Indeed, it could be admitted that for intermediate conditions inducing small initial adhesive wear domains, the progressive decreasing of the contact pressure in the lateral borders and the related increase of the interface porosity could improve the di-oxygen access. Hence, the composite adhesive/abrasive interface should evolve progressively toward a pure abrasive wear interface. 


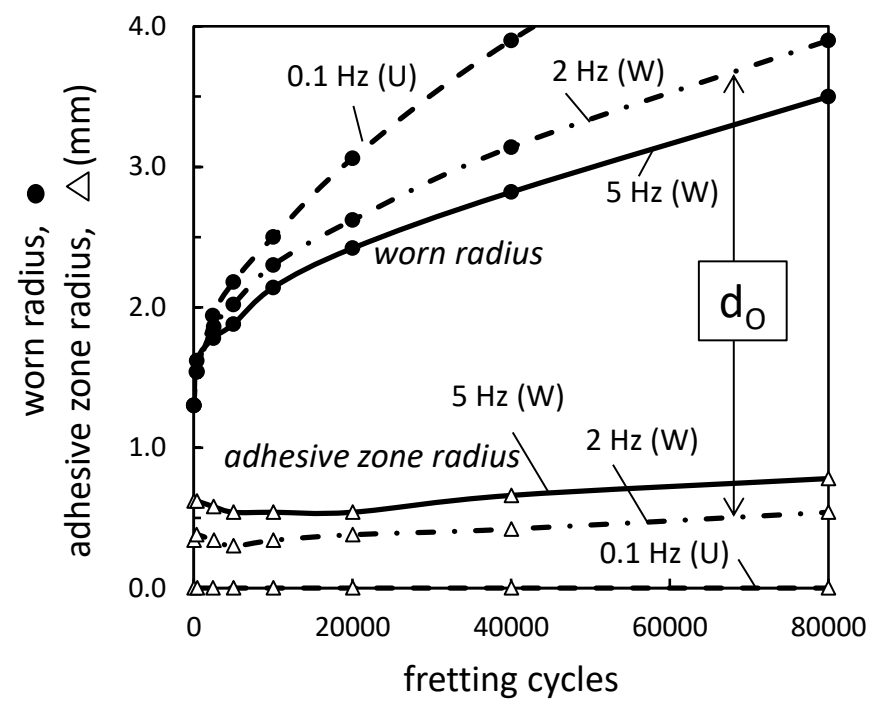

Fig. 17: Evolution of the worn contact radius and the inner adhesion domain radius predicted by the WTO simulation as a function of the applied sliding frequency: (U): "U-shape" fretting scar morphology, (W): "W-shape" fretting scar morphology (conditions: Ti-6AL-4V cylinder-on-flat interface, $R=80 \mathrm{~mm}, F_{n, L}=1066 \mathrm{~N} / \mathrm{mm}, \delta_{g}^{*}= \pm 75 \mu \mathrm{m}$ ), (Simulation parameters: Table 2).

Alternatively, the very large extension of the contact area for a pure abrasive wear process moves away the contact borders from which the $\mathrm{O}_{2}$ molecules diffuse. This phenomenon could progressively activate an inner adhesive wear domain. The very long term prediction of the $\mathrm{W}$-shape and U-shape structures is very complex and implies a kinetic balance involving numerous tribo-chemical processes which at this stage are not sufficiently detailed in the given WTO model. Current researches are undertaken to deepen this aspect improving the physical description of the model in order to simulate very long tests to achieve pertinent steady state predictions. One conclusion derived from these WTO simulations is that the pure abrasive "U-shape" and the composite adhesive-abrasive "Wshape" structures are rather stable at least for the studied medium test duration which was effectively confirmed by experiments [15].

\subsection{Contact pressure evolution}

One consequence of such a composite adhesive-abrasive surface discontinuity is the significant modification of the friction energy density and the related pressure profiles (Fig. 16). While the contact pressure on the lateral sides converges to a low flat distribution due to the worn spacing between the plane and the cylinder surfaces, a maximum pressure peak is observed in the inner adhesive domain where most of the contact load carrying is transmitted. Even in the adhesive wear domain the pressure profile is not homogeneous but displays two maximum peaks located at the 
adhesion/abrasion boundaries. These symmetrical pressure discontinuities are in fact related to the angular surface discontinuities induced by the wear rate fluctuations at these specific positions.

The fluctuation of the friction energy density profile is very fast at the beginning but tends to decelerate due to the convergence of the wear rate over the whole interface. As previously detailed in [35], the evolution of the fretting interface evolves so that the wear depth kinetics tends to be constant over the whole interface. This tendency is confirmed in Fig. 18 where the wear depth increment appears discontinuous at the beginning but evolves toward a smoother distribution with the fretting cycles' number. On the other hand, the friction energy density profile stabilizes progressively in order to compensate the discontinuous distribution of the wear coefficient within the interface such that:

$\Delta h(x)=\Delta \varphi(x) \times \alpha(x)$

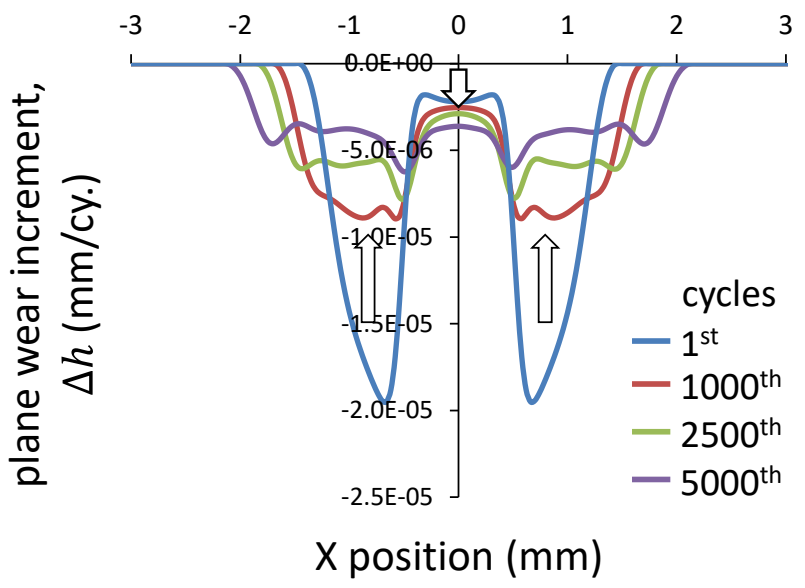

Fig. 18: Evolution of the plane increment of the wear per fretting cycle simulated by the WTO modeling (studied conditions: Ti-6AL-4V cylinder-on-flat interface, $R=80 \mathrm{~mm}, F_{n, L}=1066 \mathrm{~N} / \mathrm{mm}, \delta_{g}^{*}=$ $\pm 75 \mu m, f=2 \mathrm{~Hz}, N=5000$ cycles), (Simulation parameters: Table 2).

From this parametric investigation, it can also be concluded that contrary to what is commonly admitted, when various wear rate coefficients are operating within the interface, the pressure profiles do not converge toward a constant and decreasing pressure plateau but rather display very severe fluctuations. This effect is clearly illustrated in Fig. 19 where the maximum contact pressure computed by the model is plotted versus fretting cycles' number. As expected, when homogeneous abrasive wear processes take place $(f=0.1 \mathrm{~Hz})$, the surface wear extension induces a continuous decreasing of the peak pressure from the initial unworn Hertzian condition until low flat pressure condition. 


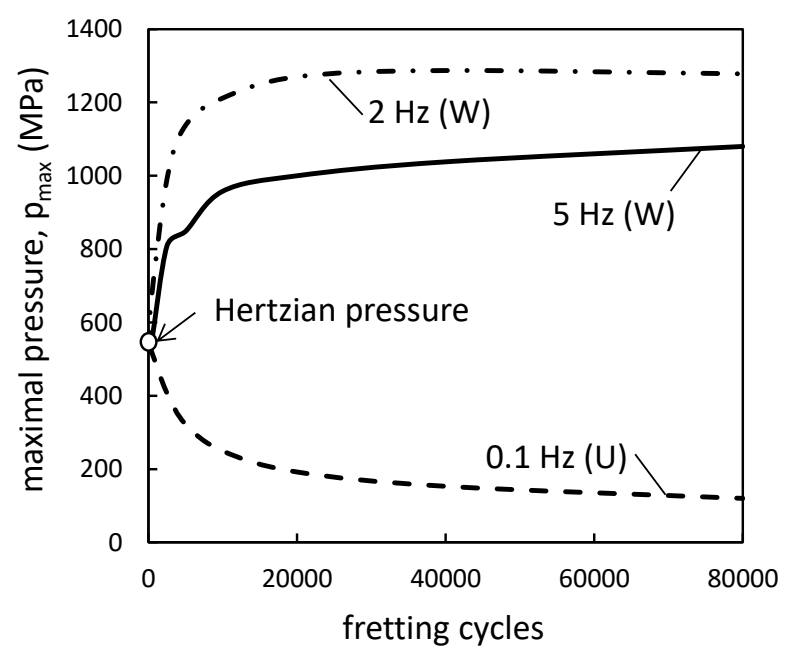

Fig. 19: Evolution of the maximum contact pressure predicted by the WTO simulation as a function of the fretting cycles for $f=0.1,2$ and $5 \mathrm{~Hz}$ : (U): "U-shape" fretting scar morphology, (W): "W-shape" fretting scar morphology (conditions: Ti-6AL-4V cylinder-on-flat interface, $R=80 \mathrm{~mm}, F_{n, L}=1066 \mathrm{~N} / \mathrm{mm}$, $\left.\delta_{g}^{*}= \pm 75 \mu \mathrm{m}\right)$, (Simulation parameters: Table 2).

By contrast, the composite $\mathrm{W}$-shape structures generated at $\mathrm{f}=2$ and $5 \mathrm{~Hz}$ display very different evolutions. As discussed previously, the discontinuous evolution of the wear coefficients between the inner adhesive and the lateral abrasive wear domains promotes a sharp increase of the maximum pressure located in the adhesive domain. This effect is even more pronounced for the intermediate $\mathrm{f}=2 \mathrm{~Hz}$ frequency condition where the maximum pressure is more than twice than the initial Hertzian value after 20000 fretting cycles. Then, as expected from the stable evolution of the inner adhesive wear domain (Fig. 17), quasi constant maximum contact pressure can be observed in Fig. 19. Besides, the comparison between the simulations performed at $\mathrm{f}=2$ and $5 \mathrm{~Hz}$ also suggests that the smaller the inner adhesive domain, the higher the discontinuity and the higher the maximum contact pressure.

\subsection{Correlation with fretting cracking damage and TTS activation}

The overpressure effect predicted by the WTO modeling under gross slip condition is very interesting because it allows explaining many experimental results which until now appear unclear (Fig. 20). For instance, assuming Mindlin's contact mechanics under partial slip condition and a homogeneous surface wear response (i.e. constant wear coefficient condition) under gross slip condition as depicted by the previous WT (Wear \& Third body) modeling, the maximum contact stress and the cyclic plastic strain deformations are predicted just at the transition between the partial and the mixed fretting regime when the maximum tangential force amplitude is applied (Fig. 20b). Then, after the partial slip regime transition (i.e. when $\% \mathrm{GS}>0 \%$ ), the contact stressing is supposed to 
decrease due to the surface wear which induces a sharp reduction of the contact pressure and the cyclic shear stress fields.

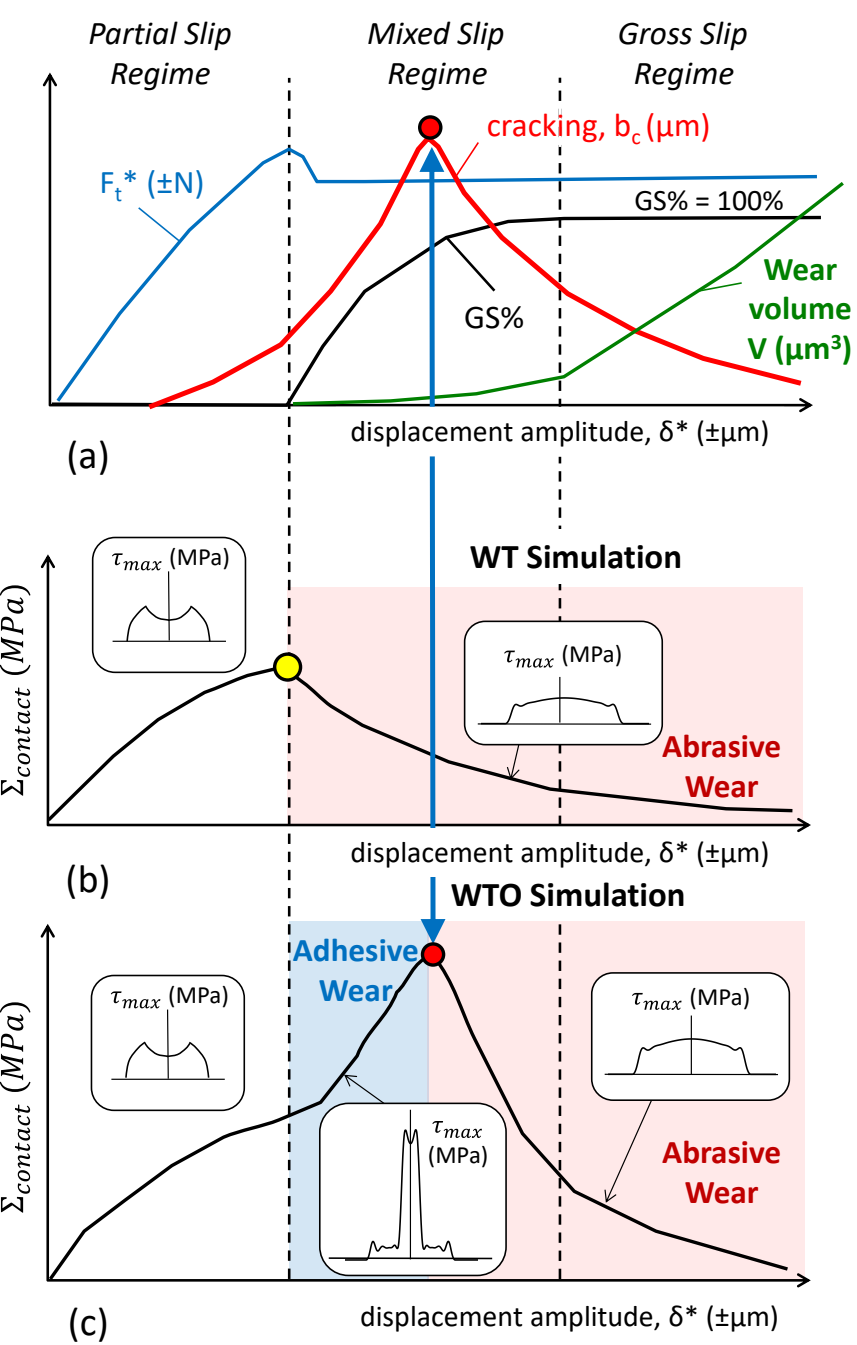

Fig. 20: Illustrating how the WTO approach could explain the activation of a maximum cracking response under mixed fretting regime: (a) schematic illustration of the tangential force amplitude $\left(F_{t}^{*}\right)$, sliding regime condition (GS\%: relative proportion of the gross slip cycles during the fretting test), crack length extension; (b) contact stress evolution as function of the displacement amplitude assuming a basic WT simulation: the maximum stressing is observed at the partial slip regime transition (i.e. GS\% = 0\%); (c) illustration of the contact stress evolution assuming a coupled WTO simulation including adhesive wear processes: adhesive wear shifts the maximum stressing to the mixed slip regime $(0 \%<G S \%<100 \%)$.

However, careful investigations of the fretting crack extension as a function of the \%GS parameter indicated that the maximum crack extension is not observed at the partial slip regime transition but rather observed in the mixed sliding regime where $90 \%$ of the fretting cycles run under gross slip conditions (i.e. \%GS = 90\%) (Fig. 20) [36]. As mentioned previously, this paradox cannot be explained 
assuming the common homogeneous surface wear hypothesis (i.e. abrasive U-shape theory). Yet, it can be perfectly interpreted using the WTO approach. The application of small gross slip amplitudes, by favoring inner adhesive wear processes, may activate overpressure conditions, over cyclic stressing and finally can explain the maximum cracking process observed in the mixed fretting regime. The following reduction of the crack extension can be also interpreted using the WTO approach. Indeed, by increasing the sliding amplitude next and above the mixed/gross slip transition (i.e. $\% \mathrm{GS}=100 \%$ ), the interface becomes better oxygenated. Then, the inner adhesive wear domain is progressively eliminated and replaced by a homogeneous abrasive wear process which, by reducing the peak pressure and removing the top cracked material, can progressively decrease the crack extension. Hence, by combining this multiphysics surface wear modeling with contact stressing analysis, it could be possible to interpret the complex competition between wear and cracking phenomena under mixed fretting regime [37].

This WTO approach could be also considered to interpret the activation of the tribologically transformed structures (TTS) in fretting interfaces [38, 39, 22]. These TTS structures, also referred to as white layers, are characterized by very high hardness (i.e. above $1000 \mathrm{Hv}$ ) displaying a similar composition as the original metal alloys (i.e. without significant concentration of oxides). Many investigations suggested that TTS are in fact induced by the cyclic plastic strain deformations generated, for instance, by fretting sliding which promotes a nano-recrystallization process (Fig. 20). By reducing the grain size below few nanometers, the Hall-Petch's theory can explain the very high hardness observed for these structures whatever the nature of the initial metal alloy. Maximum TTS thickness layer is usually observed for small - medium sliding amplitude next to the gloss slip regime transition and for medium-high pressure condition but can be also observed for low contact pressure in large contact size assemblies (Fig. 21). Besides, the TTS structure was mainly detected in the inner part of the contact and rarely in the lateral sides of the interfaces. These experimental observations are fully contradicting the predictions resulting from a conventional simulation of fretting wear assuming a homogeneous surface wear process. As discussed previously, after this hypothesis the maximum cyclic-plastic deformation should be observed at the partial slip regime transition whereas the TTS thicknesses should be located in the inner side where the maximum cyclic plastic strain deformations are supposed to take place. 


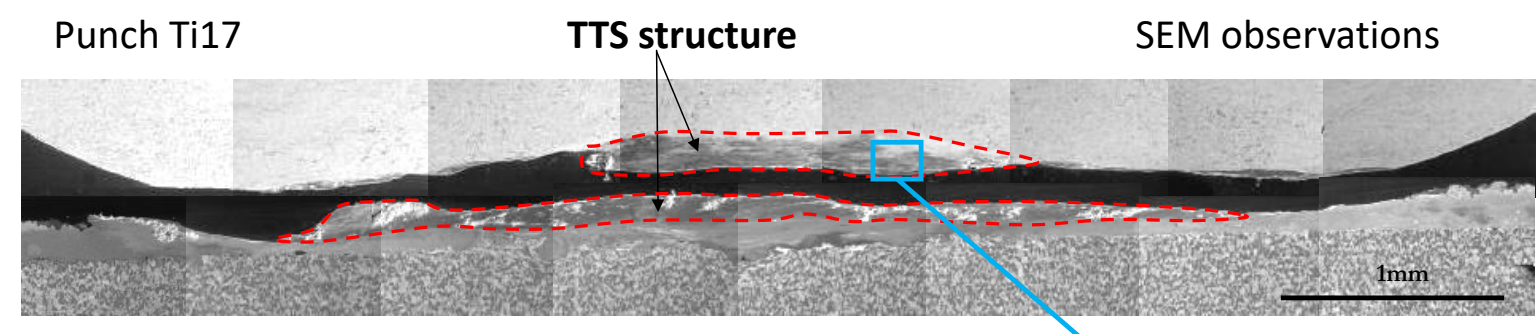

Plane: Ti6242g + CuNiln
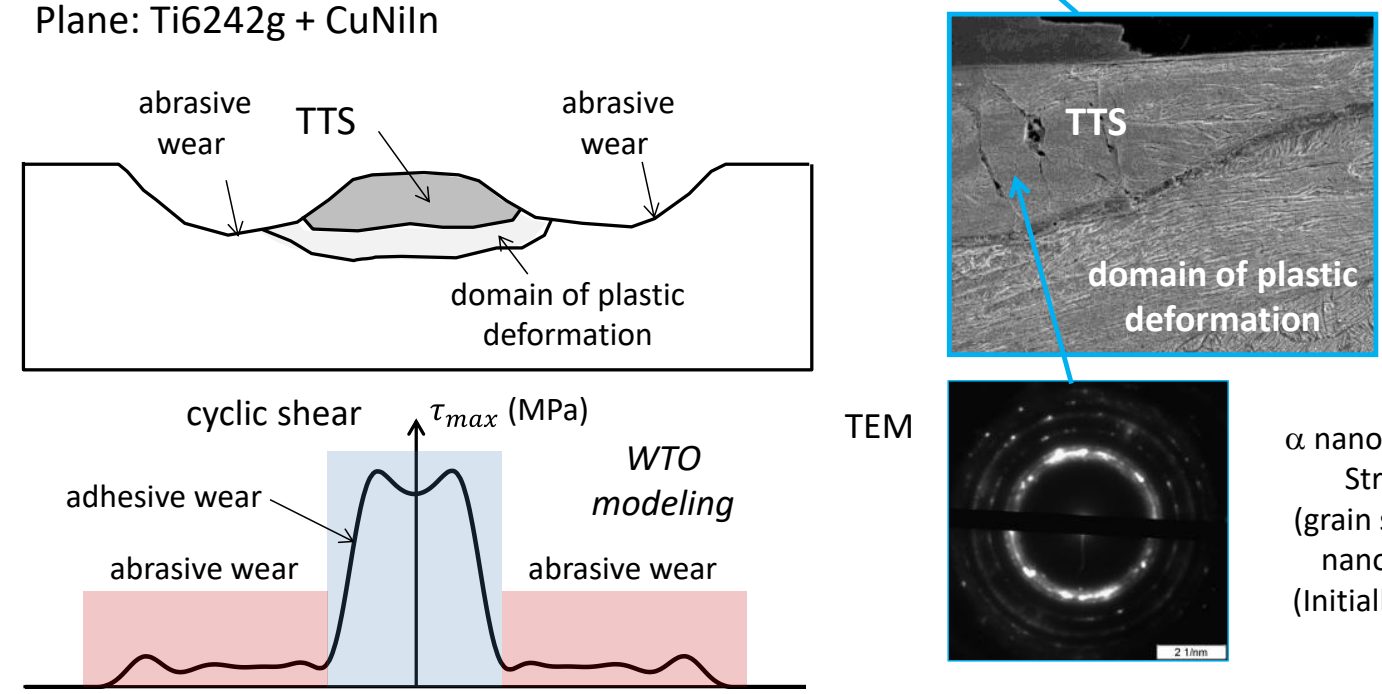

TEM

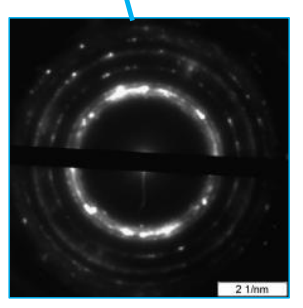

$\alpha$ nano-crystalline Structure (grain size of few nanometers) (Initially Ti17 ( $\beta)$ )

Fig. 21: Illustration of the TTS distribution observed in a fretting gross slip punch (Ti17) / plane (Ti6242 $s p+$ CuNiln coating) interface [22]. Note that a W-shape structure involving metal transfers and TTS in the inner part of the contact can be interpreted using the given WTO approach.

By contrast, the experimental investigation of the TTS formation is perfectly interpreted using the WTO approach and the related overpressure effect. Since the maximum pressure and the related cyclic shear strains are generated in the inner adhesive wear domain, it can be explained why the TTS is mainly detected in the inner part of the contact and not in the lateral sides (Fig. 21). Besides, the WTO modeling, by predicting the overpressure conditions being 2 to 3 times higher than the initial Hertzian contact pressure, can also explain why the TTS could be observed for rather low initial pressure condition particularly for large contact sizes like punch/plane contacts which promote air distilling as depicted in Fig. 7. 

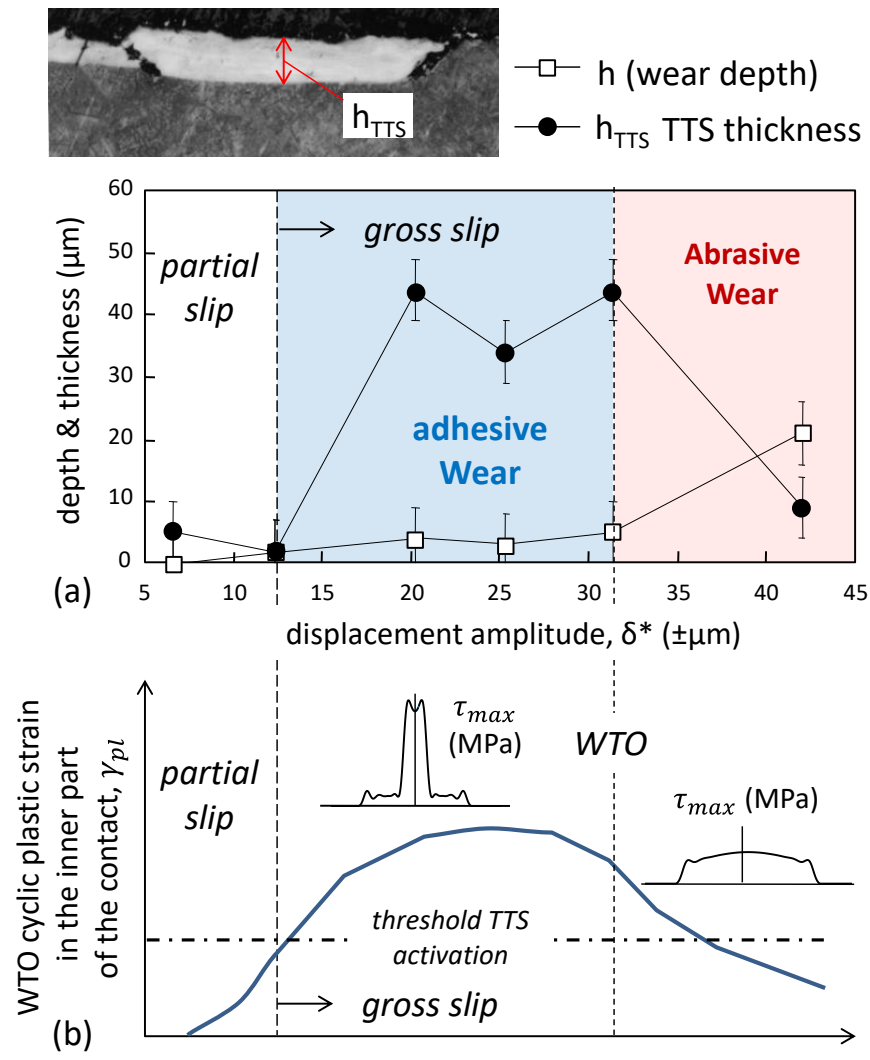

Fig. 22: (a) Illustration of the wear depth and TTS thickness generated in a 35NCD16 steel as a function of the applied displacement amplitude (after [38]); (b) Illustrating how the WTO surface wear modeling can explain the thicker TTS layer under intermediate gross slip sliding condition when adhesive wear occurs and the successive decreasing of this latter for larger sliding amplitudes when the contact becomes better oxygenated so that the interface evolves toward a higher abrasive wear rate response.

By generating very high contact pressure condition and consequently severe cyclic plastic strains in the inner adhesive domain, the WTO hypothesis also clarifies why the TTS is mainly observed for gross slip conditions next to the gross slip regime transition and not at the partial slip regime transition (Fig. 22). The WTO approach and the related contact oxygenation concept can be also considered to explain why the TTS layer decreases in size when the gross slip amplitude becomes too large [38]. By increasing the sliding amplitude, the contact oxygenation is improved, hence, the inner adhesive wear domain will be progressively erased shifting the fretting interface toward a pure abrasive wear response. One consequence of this is the fast drop of the contact pressure profile which triggers a fast decrease of the cyclic plastic strain imposed on the material so that TTS formation is no more possible. 


\section{Conclusion}

New innovative multiphysics wear modeling (i.e. WTO: Wear (friction energy) - Third body - contact Oxygenation) is developed to simulate the evolution of the fretting wear profiles. This latter consists in a local FEM friction energy density approach to simulate the wear profile evolution of the contacted surfaces taking into account the presence of the third body layer. This model is combined here with a finite difference modeling of the contact oxygenation process applying an AdvectionDispersion-Reaction (ADR) formalism. The di-oxygen partial pressure operating at the $x$-position of the interface is computed. Then, at this x-position, the interface is checked whether it is oxygenated (i.e. $P_{O 2}(x) \geq P_{O 2, t h}$ ) or under-oxygenated (i.e. $\left.P_{O 2}(x)<P_{O 2, t h}\right)$. Hence, abrasive (i.e. $\alpha_{a b}$ ) or adhesive (i.e. $\alpha_{a d}$ ) wear coefficients are considered respectively to simulate the successive wear depth increment such that $\alpha_{a b} \gg \alpha_{a d}$. This coupled approach combining mechanical damage and surface oxidation processes was applied to simulate the gross slip fretting wear response of a Ti-6Al$4 \mathrm{~V}$ cylinder-on-flat interface as a function of the sliding frequency. From this combined experimental multiphysics modeling analysis, the following points can be highlighted:

- Despite the simplicity of the model and the rather small number of variables required, the WTO approach was able, for the first time, to simulate the composite "W-shape" adhesive-abrasive fretting scar morphology. Confirming previous experimental observations, the model predicts well that the maximum wear depths are located in the lateral sides where abrasive wear process takes place and confirms a lower wear depth in the inner adhesive wear part. If the contact oxidation condition is satisfied over the whole fretted interface, the WTO model also predicts the "U-shape" structure which is experimentally observed when a full abrasive wear process is activated.

- Using this WTO approach, it was possible to predict the transition from the pure abrasive "U-Shape" to the composite adhesive-abrasive "W-Shape" fretting scar morphology when the friction power density (i.e. sliding frequency) overpasses a threshold value. A rather good correlation with the experiments confirms the stability of the model.

- Although only two friction energy wear coefficients were considered (i.e. $\alpha_{a b}, \alpha_{a d}$ ) depending if abrasive or adhesive wear is activated, the WTO model, by computing the extension of adhesive and abrasive wear areas, is able to capture the asymptotic decreasing of the global wear rate versus the frequency as observed in the experimental investigation.

- A parametric study confirms the stability of the inner adhesive wear domain which remains nearly constant whatever the extension of the worn contact radius. This suggests that the wear contact extension is mainly driven by the lateral extension of the abrasive wear domains. As expected, the larger the inner adhesive wear domain, the smoother the worn contact radius extension.

- The WTO simulations suggest that the activation of an inner adhesive wear domain, by promoting a discontinuous distribution of the wear coefficient and consequently a discontinuous surface 
geometry (i.e. "W-shape" fretting scar), generates very high pressure condition in the central adhesive wear domain. The highest pressure value is observed at the boundary between adhesive and abrasive domains. Maximum pressure values more than 2 times higher than the initial Hertzian value can be observed although gross slip and surface wear conditions operate. This overpressure effect predicted by the WTO model can be considered to explain why the main cracking damage and the TTS plastic transformations are generated under mixed fretting regime.

This multiphysics WTO modeling could be improved in many aspects. For instance, by better formalizing the third body transfer function (here approximated by a single constant), the wear profiles will be predicted better especially for the U-shape abrasive wear configurations. The global wear rate analysis also proposes that this approach could be improved by considering a variable porosity parameter depending on the nature and the compaction of the third body layer. Other improvements regarding a more progressive evolution of the local wear coefficients from adhesive to abrasive wear domains could be also considered. Finally, the long term evolution of the fretting interface appears as a key aspect to predict the steady state response of such fretting interface. Nevertheless, despite these numerous limitations, this first approach appears as a very interesting strategy to predict very complex fretting wear processes.

\section{References}

[1] Hurricks PL. The fretting wear of mild steel from room temperature to $200{ }^{\circ} \mathrm{C}$. Wear 19 (1972) 207-236.

[2] Archard JF. Contact and rubbing of flat surfaces. J Appl Phys 24 (1953) 981-988.

[3] T. Liskiewicz, S. Fouvry, B. Wendler, Development of a Wöhler-like approach to quantify the hard coatings durability under oscillating sliding conditions, Wear 259 (1-6) (2005) 835-841.

[4] H. Mohrbaker, B. Blanpain, J.P. Celis, J.R. Ross, M. Van Stappen. L. Stals and M. Van Stappen, Oxidation wear of TiN on tool steel and nitride steel in unlubricated, Wear 188 (1995) 130-137.

[5] S. Fouvry, Ph. Kapsa, L. Vincent, Quantification of fretting damage, Wear 200 (1996), 186-205

[6] A. Ramalho, J.P. Celis, High temperature fretting behaviour of plasma vapour deposition TiN coatings, Surface and Coatings Technology 155 (2-3) (2002) 169-175.

[7] L. Gallego, B. Fulleringer, S. Deyber, D. Nélias, Multiscale computation of fretting wear at the blade/disk interface, Tribol. Int. 43(4) (2010) 708-718.

[8] V.A. Yastrebov, G. Anciaux, J.F. Molinari, From infinitesimal to full contact between rough surfaces: Evolution of the contact area, International Journal of Solids and Structures 52 (2015) 83102. 
[9] I.R. McColl, J. Ding, S.B. Leen, Finite element simulation and experimental validation of fretting wear, Wear 256 (2004) 1114-1127.

[10] C. Mary, S. Fouvry, Numerical prediction of fretting contact durability using energy wear approach: Optimisation of finite-element model, Wear 263(1-6) (2007) 444-450.

[11] P. Arnaud, S. Fouvry, S. Garcin, Wear rate impact on Ti-6AI-4V fretting crack risk: Experimental and numerical comparison between cylinder-on-flat and punch/plane contact geometries, Tribology International 108 (2017) 32-47.

[12] J. Ding, I.R. McColl, S.B. Leen, P.H. Shipway, A finite element based approach to simulating the effects of debris on fretting wear, Wear 263 (2007) 481-491.

[13] S. Basseville, G. Cailletaud, An evolution of the competition between wear and crack initiation in fretting conditions for Ti-6Al-4V alloy, Wear 328-329 (2015) 443-455.

[14] P. Arnaud, S. Fouvry, A dynamical FEA fretting wear modeling taking into account the evolution of debris layer, Wear 412-413 (2018) 92-108.

[15] S. Fouvry , P. Arnaud, A. Mignot, P. Neubauer, Contact size, frequency and cyclic normal force effects on Ti-6Al-4V fretting wear processes: An approach combining friction power and contact oxygenation, Tribology International 113 (2017) 460-473.

[16] S. Baydoun, P. Arnaud, S. Fouvry, Modelling adhesive wear extension in fretting interfaces: An advection-dispersion-reaction contact oxygenation approach, Tribology International 151 (2020) 106490

[17] A. Iwabuchi , T. Kayaba, K. Kato, Effect of atmospheric pressure on friction and wear of $0.45 \%$ C steel in fretting, Wear 91 (1983) 289-305.

[18] J.J. Madge, S. B. Leen SB, I.R. McColl, P.H. Shipway, Contact-evolution based prediction of fretting fatigue life: effect of slip amplitude, Wear 262(9-10) (2007) 1159-1170.

[19] T. Yue, A. I. Wahab Finite element analysis of fretting wear under variable coefficient of friction and different contact regimes, Tribology International 107 (2017) 274-282

[20] Y. Berthier, L. Vincent, M. Godet, Velocity accommodation in fretting, Wear 125 (1-2) (1988) 2538.

[21] N. Fillot, I. Iordanoff, Y. Berthier, Wear modeling and third body concept, Wear 262

(2007) 949-957.

[22] C. Mary, S. Fouvry, J.M. Martin, B. Bonnet, Pressure and temperature effects on Fretting Wear damage of a Cu-Ni-In plasma coating versus Ti17 titanium alloy contact, Wear, 2011, 272 (1, 3):1837

[23] A. Warmuth, S. Pearson, P. Shipway, W. Sun. The effect of contact geometry on fretting wear rates and mechanisms for a high strength steel. Wear 301 (2013) 491-500 
[24] S. Baydoun, S. Fouvry An experimental investigation of adhesive wear extension in fretting interface: Application of the contact oxygenation concept, Tribology International 147 (2020) 106266 [25] H. Darcy, Les fontaines publiques de la ville de Dijon. V. Dalamont (1856).

[26] C.R. Wilke, A viscosity equation for gas mixtures, J Chem Phys 18 (1950) 517-526

[27] P.C. Carman, Flow of gases through porous media. Butterworths Scientific Publications (1956)

[28] A. Fick, Ueber diffusion, ann. Phys 170 (1855) 59-86

[29] M.S. Costanza-Robinson, M.L. Brusseau, Gas-phase dispersion in porous media. In: Gas transp. Porous Media;(2006) 121-132

[30] V. B. Stein, J.P. Hettiaratchi, G. Achari, Numerical model for biological oxidation and migration of methane in soils, Am. Soc. Civ. Eng. 5 (2001) 225-234.

[31] P.J. Binning, D. Postma, T.F. Russell, J.A. Wesselingh, P.F. Boulin, Advective and diffusive contributions to reactive gas transport during pyrite oxidation in the unsaturated zone, Water Resour. Res 43 (2007) 1-12.

[32] Pickens JF, Grisak GE. Scale-dependent dispersion in a stratified granular aquifer Water Resour Res 1981;17:1191-211.

[33] N. Ouchlyama, T. Tanaka. Porosity estimation from particle size distribution. Ind Eng Chem Fundam 25 (1986) 125-134.

[34] D.R. Lide, CRC handbook of chemistry and physics, $90^{\text {th }}$ Ed. 2009, CRC Press, Boca Raton.

[35] S. Fouvry, T. Liskiewicz, C. Paulin, A global-local wear approach to quantify the contact endurance under reciprocating-fretting sliding conditions, Wear 263 (1-6) (2007) 518-531.

[36] S. Heredia, S. Fouvry, Introduction of a new sliding regime criterion to quantify partial, mixed and gross slip fretting regimes: Correlation with wear and cracking processes, Wear, 2010, 269 (7-8) : 515-524.

[37] Z.R. Zhou, L. Vincent, Mixed fretting regime, Wear 181-183 (1995) 531-536

[38] E. Sauger, S. Fouvry, L. Ponsonnet, J.M. Martin , Ph. Kapsa, L. Vincent Tribologically Transformed Structure in Fretting, Wear 245, 2000, p.39-52.

[39] S. Descartes, M. Busquet, Y. Berthier, An attempt to produce ex situ TTS to understand their mechanical formation conditions - The case of an ultra high purity iron, Wear 271 (2011) 1833-1841 